OPEN ACCESS

Edited by:

Léo Aubert,

Montreal University, Canada

Reviewed by:

Feng Wang,

Affiliated Hospital of Nantong

University, China

Caroline Lamb,

CONICET Instituto de Biología y Medicina Experimental (IBYME),

Argentina

*Correspondence:

Haijun Wang

wnavy200299@163.com

Na Song

sarah_song1986@163.com

Specialty section:

This article was submitted to Pharmacology of Anti-Cancer Drugs,

a section of the journal

Frontiers in Pharmacology

Received: 11 January 2021

Accepted: 11 March 2021

Published: 15 April 2021

Citation:

Wang H, Yang J, Zhang K, Liu J, Li Y, Su W and Song N (2021) Advances of Fibroblast Growth Factor/Receptor Signaling Pathway in Hepatocellular

Carcinoma and its

Pharmacotherapeutic Targets.

Front. Pharmacol. 12:650388. doi: 10.3389/fphar.2021.650388

\section{Advances of Fibroblast Growth Factor/Receptor Signaling Pathway in Hepatocellular Carcinoma and its Pharmacotherapeutic Targets}

\author{
Haijun Wang ${ }^{1,2 *}$, Jie Yang ${ }^{2}$, Ke Zhang ${ }^{2}$, Jia Liu ${ }^{2}$, Yushan $L^{3}{ }^{3}$, Wei Su ${ }^{1}$ and Na Song ${ }^{2,4 *}$ \\ ${ }^{1}$ Key Laboratory of Clinical Molecular Pathology, Department of Pathology, The First Affiliated Hospital of Xinxiang Medical \\ University, Xinxiang, China, ${ }^{2}$ School of Basic Medical Sciences, Xinxiang Medical University, Xinxiang, China, ${ }^{3}$ School of Public \\ Health, Xinxiang Medical University, Xinxiang, China, ${ }^{4}$ Institute of Precision Medicine, Xinxiang Medical University, Xinxiang, China
}

Hepatocellular carcinoma $(\mathrm{HCC})$ is a type of primary liver cancer with poor prognosis, and its incidence and mortality rate are increasing worldwide. It is refractory to conventional chemotherapy and radiotherapy owing to its high tumor heterogeneity. Accumulated genetic alterations and aberrant cell signaling pathway have been characterized in HCC. The fibroblast growth factor (FGF) family and their receptors (FGFRs) are involved in diverse biological activities, including embryonic development, proliferation, differentiation, survival, angiogenesis, and migration, etc. Data mining results of The Cancer Genome Atlas demonstrate high levels of FGF and/or FGFR expression in HCC tumors compared with normal tissues. Moreover, substantial evidence indicates that the FGF/FGFR signaling axis plays an important role in various mechanisms that contribute to HCC development. At present, several inhibitors targeting FGF/FGFR, such as multikinase inhibitors, specific FGFR4 inhibitors, and FGF ligand traps, exhibit antitumor activity in preclinical or early development phases in HCC. In this review, we summarize the research progress regarding the molecular implications of FGF/FGFR-mediated signaling and the development of FGFR-targeted therapeutics in hepatocarcinogenesis.

Keywords: fibroblast growth factor, fibroblast growth factor receptor, signaling pathway, hepatocellular carcinoma, pharmacotherapeutic targets

\section{INTRODUCTION}

Hepatocellular carcinoma (HCC) accounts for $85-90 \%$ of primary liver cancer and is commonly associated with underlying chronic liver disease arising from viral infection, metabolic disorders, or alcohol abuse (Best et al., 2017). Primary liver cancer has become the sixth most common cancer in terms of incidence and is the third cause of cancer-related mortality worldwide (Sung et al., 2021). Despite some improvements in overall survival, the prognosis of patients with HCC remains poor; the ratio of estimated number of deaths to incident cases is $75 \%$ (Craig et al., 2019). According to the Global Cancer Observatory data, the mortality of HCC will be 1.28 million in 2040 vs. 0.78 million in 2018 (a 64.3\% increase), and the incidence will increase by $61.9 \%$ (from 1.36 to 0.84 million). The incidence of HCC has a certain gender orientation, with males having a higher risk. The ratio of HCC incidence is 13.9/4.9 per 100,000 people in the world, and the value is 27.6/9.0 in China. Eastern Asia is recognized as the traditionally highest-risk region, especially Japan and China. 
Generally, surgery is the predominant therapy for HCC (Bruix et al., 2005; Llovet et al., 2015). However, the outcome is poor, and the risk of recurrence and metastasis remains high even after surgery. Biological therapy is a promising therapy in a series of cancers that targets the biomarkers or signaling pathway. The development of HCC is a multistep process, in which epigenetic changes and genetic alterations accumulate in HCC cells, including mutations and DNA amplification variations, which result in cell signaling pathway variation, ultimately leading to the high heterogeneity of HCC (Moeini et al., 2012).

The fibroblast growth factor (FGF) family and their receptors (FGFRs) play crucial roles in regulating physiologic cellular processes, and they contribute to embryonic development, proliferation, differentiation, survival, angiogenesis, and migration (Turner and Grose, 2010; Yun et al., 2010; Sandhu et al., 2014). The deregulation of FGF signaling is frequently observed in HCC and liver cirrhosis, as well as viral hepatitis. Evidence shows that the FGF family and FGFRs can be used to elucidate the development and progression of HCC, even its treatment (Motoo et al., 1993; Beenken and Mohammadi, 2009). In this review, we summarize the current research progress regarding FGF/FGFR signaling in hepatocarcinogenesis and the potential pharmacological applications of FGFRs in HCC.

\section{Overview of FGFS and FGFRS}

FGFs are polypeptide growth factors that regulate diverse biological activities, ranging from cell growth, development, differentiation, wound repair to angiogenesis and tumorigenesis (Beenken and Mohammadi, 2009; Ornitz and Itoh, 2015). The first FGF-like factor with mitogenic activity was discovered in 1939 and isolated in the 1970s (Gospodarowicz et al., 1974). The human-mouse FGF family comprises 22 related proteins with similar structure and evolution, FGF1-FGF23 (Beenken and Mohammadi, 2009; Cheng et al., 2011). However, FGF19 only exists in humans, not in mice; it is highly homologous with FGF15 in mice, which are also referred as FGF15/FGF19 (Itoh, 2010). The FGF family is divided into seven subfamilies according to gene evolution analysis: FGF/1/2/5, FGF3/4/6, FGF7/10/22, FGF8/17/18, FGF9/16/20, FGF11/12/13/14, and FGF15/19/21/23. FGF members are also classified into paracrine, endocrine, and intracrine FGFs on the basis of their mechanisms of action. The FGF11 subfamily belongs to intracrine FGFs, the FGF19 subfamily is recognized as endocrine FGFs, while the other 15 members of FGFs are paracrine cytokines (Itoh and Ornitz, 2008; Itoh and Ornitz, 2011).

FGFs, especially paracrine and endocrine FGFs, transduce cell signals via binding to and activating tyrosine kinase receptors (FGFRs) on the surface of the target cells (Eswarakumar et al., 2005). The human FGFR gene family consists of four members, FGFR1-4. Except for FGFR4, the other types of FGFRs encode two alternative splicing variants (b and $c$ ). Therefore, seven forms of FGFR proteins with distinct ligand-binding specificity exist in humans, FGFRs $1 b, 1 c, 2 b, 2 c, 3 b, 3 c$, and 4 (Ornitz and Itoh, 2015). In the binding of FGFs-FGFRs, heparin/heparan sulfate (HS) and klotho family members $(\alpha, \beta)$ are needed as co-receptors (Ornitz and Itoh, 2015). Generally, paracrine FGFs bind to and activate FGFRs with heparin/HS, and mediate multiple developmental and physiological processes. By contrast, endocrine FGFs (FGF15/19/21/23), with a low affinity to HS, usually require the klotho proteins for high affinity binding and activating FGFRs in multiple metabolic processes and carcinogenesis (Itoh, 2010). Research reports that only a few endocrine FGF affect the progression of HCC (Ornitz and Itoh, 2015). The specific interaction of FGFs-FGFRs with cofactors activates several intracellular cascades, including Ras/MAPK, PI3K/Akt, and PLC $\gamma /$ PKC pathways, to regulate target genes transcription (Katoh and Nakagama, 2014). Abnormalities of FGFs/FGFRs will lead to many diseases and are considered as a risk factor in the development of cancer (Itoh, 2010; Touat et al., 2015; Mikhaylenko et al., 2018). The gene transcription level (Figure 1A) and mutation status of (Figure 1B) FGFs/FGFRs were also investigated in HCC patients based on GEPIA2 and cBioPortal database (Cerami et al., 2012; Gao et al., 2013; Tang et al., 2017; Tang et al., 2019). As shown in Figure 1A, the transcription levels of FGF1, 2, 7, 11-13, 17-19, and 21-22 and FGFR1-4 in hepatocellular tumor tissues are higher than those in normal tissues (Figure 1A); In addition, gene mutations, fusions, and copy number amplification of FGFs/FGFRs are closely related to the occurrence of HCC. As shown in Figure 1B, FGF1, 3-7, 9-22 and FGFR1-4 all have different degrees of genetic changes, especially gene copy number amplification and deep deletion. Moreover, the FGF1 subfamily and FGF18 could promote angiogenesis, FGF15/19 binding with FGFR4 can be used as a potential biomarker in HCC. Above all, there is a growing interest in targeted agents based on FGF and FGFR for HCC, relevant clinical trials are being carried out, such as brivanib, dovitinib, FGF401, and BLU-554 (Katoh and Nakagama, 2014; Katoh, 2016; Spallanzani et al., 2018; Lu et al., 2019; Subbiah and Pal, 2019; Weiss et al., 2019).

\section{FGF1 Subfamily}

FGF1 (aFGF) and FGF2 (bFGF) are the first discovered FGF family members, which were originally isolated from the brain and pituitary gland (Gospodarowicz, 1975; Gambarini and Armelin, 1982; Lemmon and Bradshaw, 1983). The amino acid homology between FGF1 and FGF2, which belong to the FGF1 subfamily, is as high as $55 \%$. Due to the lack of a signal sequence and no secretion, FGF1 and FGF2 cross the membrane through a process facilitated by binding the cell surface and extracellular matrix (ECM) heparan sulfate (HS). FGF1 subfamily members function through an autocrine manner, inducing HCC proliferation, invasion, and angiogenesis (Kin et al., 1997). The expression of FGF1 and FGF2 is induced in chronic liver diseases, and their expression levels are increased in more advanced tumor stages (Jin-no et al., 1997; Poon et al., 2001; Asada et al., 2003; Cheng et al., 2011; Sandhu et al., 2014).

Compared with FGF1, the oncogenetic effect of FGF2 in various tumors has been studied (Baird and Klagsbrun, 1991; Beenken and Mohammadi, 2009; Cheng et al., 2011; Sandhu et al., 2014; Itoh et al., 2016). In mice transplanted with HCC cells, antibasic FGF antibody injection slowed down and suppressed tumor growth. The deregulation of FGFR3 with specific siRNA inhibits the HCC cell growth, indicating that FGF2 and its receptors 

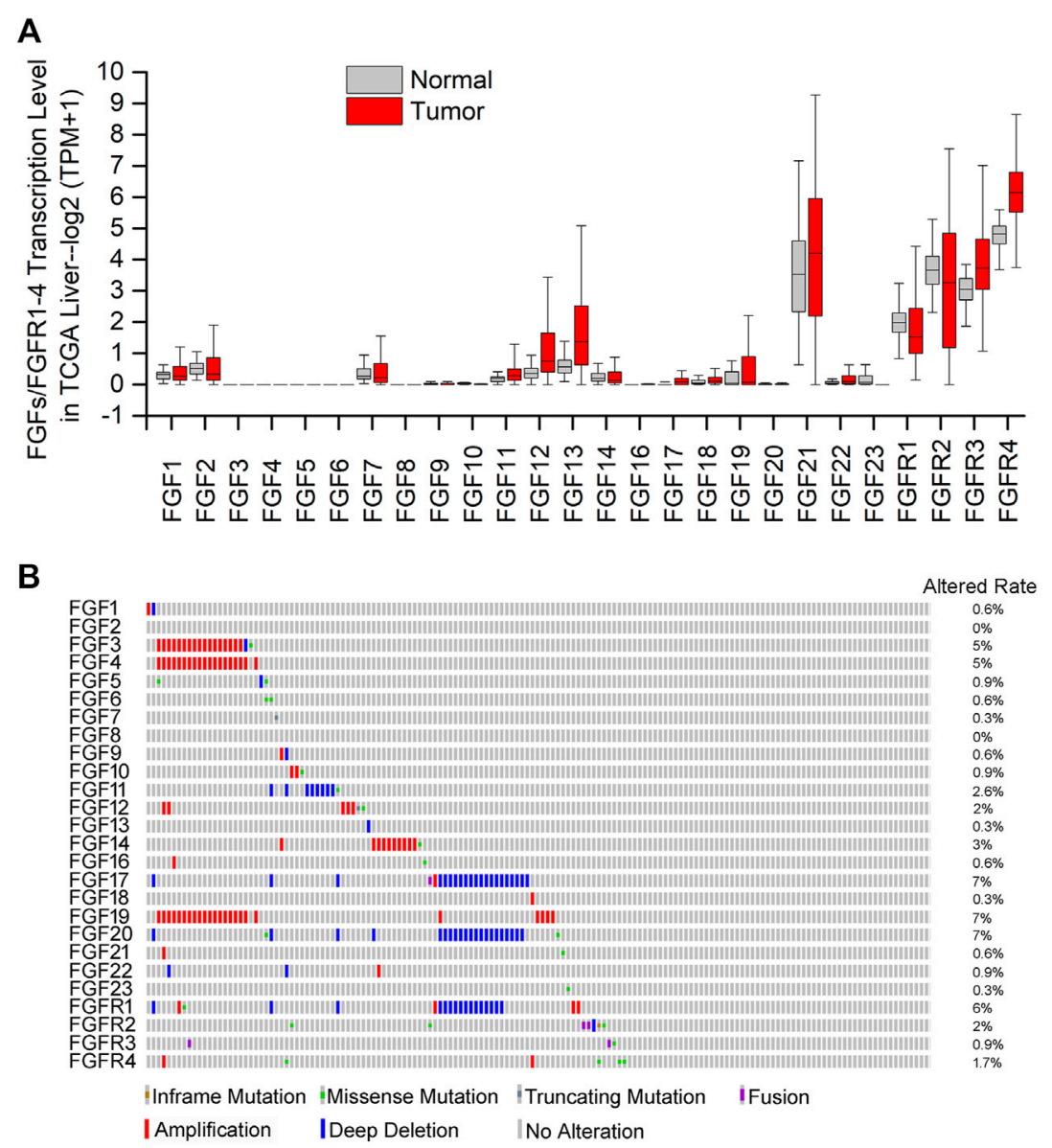

FIGURE 1 | Gene transcription level and mutation status of FGFs/FGFRs in HCC patients were investigated with TCGA database analysis (A) The transcription levels of FGF1-23 and FGFR1-4 was investigated with GEPIA platform (http://gepia.cancer-pku.cn/) between HCC tumor vs. normal samples based on TCGA database (B) The mutation status of FGF1-23 and FGFR1-4 was displayed based on cBioPortal database (https://www.cbioportal.org/). Altered rate: altered/total profiled.

(FGFR3) are essential for HCC proliferation (Poon et al., 2001; Midorikawa et al., 2003). Several studies suggested that FGF2 expression is correlated with the invasiveness and postsurgical survival of HCC (Poon et al., 2001; Poon et al., 2003).

HCC is a devastating disease with high angiogenesis. FGF1 and FGF2 are correlated with increased sinusoidal capillarization, which is involved in tumor angiogenesis (Motoo et al., 1993). It was supported that blocking FGF2 with vascularization inhibitors leads to a significant reduction in tumor size (Wang and Becker, 1997). FGF2 and VEGF acted synergistically in tumor angiogenesis to accelerate tumor progression, at least on the angiogenic maintenance of tumors in HCC patients (Wang and Becker, 1997; Yoshiji et al., 2002). Furthermore, increased levels of FGF2 were detected in the serum of cancer patients who have become resistant to VEGF-targeted therapy, which suggests the indirect role of FGF2 in angiogenic resistance. Thus, dual targeting of VEGF/FGF is a considerable strategy to circumvent therapy resistance (Casanovas et al., 2005). The latest research claimed that FGF2 single nucleotide polymorphisms (SNPs) rs308379 A allele could be regarded as an independent poor prognostic factor for overall survival in patients with HBV-associated HCC by multivariate Cox analysis (Kim et al., 2019b). Taken together, FGF1 and FGF2 are believed to be of great importance in the development of HCC.

\section{FGF8 Subfamily}

FGF8, FGF17, and FGF18 are members of the FGF8 subfamily with strong homology and evolutionary relationship (Gauglhofer et al., 2011). Four FGF8 isoforms exist for alternative splicing. These FGF8 variants, FGF17, and FGF18, which act as local paracrine molecules, are presumed to bind and activate FGFR2, FGFR3, and FGFR4 (Zhang et al., 2006; Beenken and Mohammadi, 2009). The FGF8 subfamily exerts oncogenic effects in HCC. According to statistics, at least one member of the FGF8 subfamily and/or their receptors is upregulated to facilitate cell survival and angiogenesis via activating ERK in the majority of HCC cases studied (Gauglhofer et al., 2011). FGF8, FGF17, and FGF18 seem to be important drivers of proliferation, malignant behavior, and neovascularization in advanced stages of HCC. The proliferation and neovascularization of myofibroblasts (MFs) cultured from HCCs can be induced by additional FGF8 subfamily members via the modulation of VEGF pathways 
(Alessandri et al., 1998). The administration of FGF8, FGF17, or FGF18 could resist apoptosis and enhance the survival of serumstarved tumor cells, including HCC-1.2, HepG2, and Hep3B cells, the mechanism studies have found that these effects were mediated by ERK and AKT/mTOR signaling pathways (Gauglhofer et al., 2011; Liu et al., 2015a). Therefore, the role of FGF8 subfamily members in the occurrence and development of HCC should not be neglected. Most studies on the current FGF8 subfamily in HCC mainly focused on FGF8 and FGF18. We will elaborate the activity and mechanism of these FGFs in HCC, as outlined in the following.

FGF8 was first identified in the SC-3 cell line, which is a mammary carcinoma cell line of Shionogi mouse and induced by androgen (Chen et al., 2016; Linscott and Chung, 2016). FGF8 was found to be overexpressed in several solid cancers, including HCC, but rarely detected in normal adult tissues (Liu et al., 2015a). Zou et al. confirmed that FGF8 is one of the advanced markers in stage III-IV HCC tumors with The Cancer Genome Atlas (TCGA) data and in vitro as well as in vivo. Their study also demonstrated that increased FGF17 plays a prediction role in stage II-IV HCC tumors. FGF19 and FGF4 are significantly upregulated in stage I and function as early markers (which will be described in detail in the FGF19 subfamily section) (Zou et al., 2018). The overexpressed or exogenous recombinant FGF8 promotes HCC cell growth by mediating the YAP1/EGFR axis. Meanwhile, exogenous recombinant FGF8 plays a critical role in the resistance to EGFR inhibitor gefitinib in HCC cells, but not to other anticancer chemotherapeutic drugs, such as doxorubicin, 5$\mathrm{Fu}$, paclitaxel, RAD001, and oxaliplatin (Liu et al., 2015a).

FGF18 is conserved among different species, including humans, mouse, and rats, whose amino acid identity is 99\% (Hu et al., 1998; Ohbayashi et al., 1998; Haque et al., 2007). Similar to FGF2, FGF18 also acts as a mitogen in embryonic limb development and is especially required in the development of bone, cartilage, and alveologenesis (Hajihosseini and Heath, 2002; Liu et al., 2007; Hung et al., 2016; Zhang et al., 2019a; Wang et al., 2019; Antunes et al., 2020; Hagan et al., 2020). FGF18 plays a key role in regulating the biological activity of tumor cells and immediately surrounding tissue cells of the tumor microenvironment via multiple signaling pathways (Shimokawa et al., 2003; Sonvilla et al., 2008; Gauglhofer et al., 2011; Zhang et al., 2019a; Zhang et al., 2019b; Jomrich et al., 2019). Pronounced overexpression of FGF18 accelerates tumorigenesis via mediating cell proliferation, invasion, and angiogenesis, which is correlated with poor overall survival in patients and has been addressed in multiple types of cancers, such as HCC, colorectal carcinomas, ovarian cancers, and gastric cancer (Gauglhofer et al., 2011; Koneczny et al., 2015; El-Gendi et al., 2016; Flannery et al., 2016; Zhang et al., 2019a; Zhang et al., 2019b; Jomrich et al., 2019; Kulbe et al., 2019). Animal studies also confirmed the oncogenic role of FGF18. FGF18 overexpression in the liver of transgenic mice induced a marked increase in liver weight and hepatocyte proliferation (Reinhold and Naski, 2007). Significantly increased expression levels of FGF18 were detected in rat hepatocellular adenoma and carcinoma via the autocrine pathway. Studies demonstrated that the oncogenic role of FGF18 could be directly suppressed by miR-139 in HepG2 and Huh7 cells, the downregulation of FGF18 is related to the inhibition of cell invasion, migration, angiogenesis and promotion of apoptosis (Yang et al., 2017). Similarly, silencing FGF18 with specific siRNA decreased the viability and clonal proliferation of HCC cell lines, but elevated apoptotic activity in HCC cell lines (Gauglhofer et al., 2011).

Of note, various growth factor systems in the liver tumor microenvironment of inflammatory cells, small vessels, MFs, and ECM components will accelerate hepatocarcinogenesis (Sagmeister et al., 2008). FGF8 subfamily members are related to tumor-stroma communication. FGF18 and FGF17 contribute to replicative DNA synthesis in MFs. Moreover, all FGF8 subfamily members participate in the tube formation of endothelial cells, which is essential for neoangiogenesis (Gauglhofer et al., 2011). FGF18 increases protein synthesis and cell growth to induce HCC vascularization in liverspecific endothelial cells, which are associated with the function of ribosomal protein RPS6 (Clevers, 2000). Consistently, FGF18 expression and secretion are upregulated in a high-RPS15 Aexpression HCC tumor microenvironment; FGF18 interacts with FGFR3 and contributes to angiogenesis by inducing the Wnt/ $\beta$-catenin signaling pathway in endothelial cells (Guo et al., 2018). Similar to other FGFs, FGF18 also prefers to induce the formation of new blood vessels in HCC via directly or indirectly regulating VEGF of tumor cells and surrounding tissue cells of the tumor microenvironment. Taken together, FGF18 contributes to the progression of HCC via paracrine and autocrine ways.

\section{FGF19 Subfamily}

The FGF19 subfamily consists of FGF15/19, FGF21, and FGF23. Although Fgf15/19, FGF21, and FGF23 have only about 22-35\% amino acid identity, phylogenetic and gene locus analyses suggested that they belong to one subfamily (Itoh and Ornitz, 2004, 2008; Mikhaylenko et al., 2018). FGF15 and FGF19 are the mouse and human orthologs, respectively, which share 53\% amino acid homology. We refer to them collectively as FGF15/19 unless referring to a specific ortholog (Itoh and Ornitz, 2011). FGF19 subfamily members have been identified in vertebrates but not invertebrates (Itoh and Ornitz, 2004; Itoh, 2007). In contrast to other FGFs, FGF19 subfamily members act in an endocrine way because of the low binding affinity to HS, which facilitates their diffusion over long distances from the tissue of production and the secretory area, and act as endocrine hormones (Zhang et al., 2006; Goetz et al., 2007; Itoh, 2010; Tulin and Stathopoulos, 2010; Beenken and Mohammadi, 2012). Endocrine FGFs need the assistance of klotho proteins to adjust the interaction of FGFs and corresponding FGFRs to mediate biological activity via triggering classical FGF pathways (Choi et al., 2006; Beenken and Mohammadi, 2012; Kuroo, 2012). FGF23 activates FGFR1c via binding with $a$-klotho, which originates from the bone, secreted by osteocytes/osteoblasts, but is responsible for phosphate homeostasis and vitamin $\mathrm{D}$ administration in the kidney (Urakawa et al., 2006; Fon Tacer et al., 2010; Ersoy, 2014; Fukumoto, 2019; Pereira et al., 2019). Targeted ablation of FGF23 in mice causes severe hyperphosphatemia, along with osteoporosis, vascular calcification, atherosclerosis, sterility, and survival reduction but no significant effect on liver diseases (Shimada et al., 2004).

Compared with FGF23, FGF15/19 and FGF21 need $\beta$-klotho (KLB) as co-receptor to bind to their FGFRs. Both of them can activate the IIIc isoform of FGFR1, two and 3. However, only FGF19 
activates FGFR4 in vitro. The abundant expression of $\beta$-klotho in the liver indicates that FGF15/19 and FGF21 act in the liver, which has been confirmed by multiple studies (Kharitonenkov et al., 2008; Yang et al., 2012a; Ding et al., 2012; Schumann et al., 2016; Agrawal et al., 2018; Ritchie et al., 2020). FGF19 is involved in postprandial gut-liver communications and acts as a growth factor for hepatocytes as well as hepatic bile acid synthesis (Kir et al., 2011). However, numerous pieces of evidence indicated that FGF15/19 is not physiologically expressed in the liver, but pathological FGF19 expression was detected in liver tissues of patients with liver diseases, including hepatitis $\mathrm{C}$ virus cirrhosis, cholestasis, and HCC (Inagaki et al., 2007; Naugler et al., 2015). FGF15/19 function as a driver for HCC (Miura et al., 2012; Mellor, 2014; Repana and Ross, 2015; Li et al., 2016b; Cui et al., 2018; Lin et al., 2019b Maeda et al., 2019; Raja et al., 2019). FGF21 is predominantly produced by the liver and also expressed in adipose tissue, skeletal muscle, pancreas, and many other organs. FGF21 is now considered as a key regulator of stress response in humans (Luo et al., 2017; Wu et al., 2017). Under stress conditions, elevated circulating FGF21 levels mostly appear to be derived from the liver, which has been confirmed in a series of liver-related disease models, such as liver inflammation; liver injury elicited by ethanol, drugs, or ischemia/reperfusion; liver regeneration; and hepatocarcinogenesis (Yang et al., 2013a; Ye et al., 2014; Ye et al., 2016; Desai et al., 2017; Wu et al., 2017; Ritchie et al., 2020). Taken together, the liver is recognized as a major direct or indirect target organ for FGF15/19 and FGF21 because of their expression in the liver with physiological and pathological conditions. Meanwhile, $\beta$ klotho and FGFR4 are predominantly expressed in the liver. Therefore, FGF15/19 or FGF21, FGFR4, and $\beta$-klotho coreceptor signaling system play as key regulators in hepatocarcinogenesis (Alvarez-Sola et al., 2017). Here, we will review the role of FGF15/19 and FGF21 on HCC in detail.

Abnormal FGF15/19-FGFR4 signaling pathway is an important cause of HCC, which is a complex and strongly heterogeneous type of cancer. Through genomic analysis, FGF19 gene amplification has been characterized in a subset of HCC tumors from patients with poor prognosis, and the expression of FGF19 is almost $48 \%$ in resected HCCs. After curative resection, circulating levels of FGF19 in HCC patients decreased. Furthermore, FGF19 protein expression in HCC tissues is significantly related to larger tumor size, advanced disease stage, and early recurrence (Sawey et al., 2011; Miura et al., 2012). In childhood hepatoblastoma, FGF19 gene amplification is not as prevalent as in adult HCC (approximately 5\%) but significantly related to the degree of aggressiveness (Elzi et al., 2016). Animal studies showed that muscle-specific FGF19 transgenic mice at 10 months of age were used to generate liver cancer formation (Nicholes et al., 2002). And FGF15 participates in liver regeneration after partial hepatectomy inducing hepatocellular proliferation, $\mathrm{FGF} 15^{-/-}$mice showed lesser and smaller tumors, and histological neoplastic lesions were also smaller than those in $\mathrm{FGF}^{+/+}$animals (Uriarte et al., 2015). The above studies proved that high levels of FGF19 contribute to the development of HCC, function as an independent prognostic factor for survival, and may predict early recurrence of HCC after curative hepatectomy (Miura et al., 2012; Li et al., 2016b; Alvarez-Sola et al., 2017; Gao et al., 2017; Cui et al., 2018; Raja et al., 2019).
The function of FGF19 is dependent on the expression of FGFR4 and KLB (Kurosu et al., 2007; Lin et al., 2007; Fon Tacer et al., 2010). Increased expression of FGFR4 or KLB and the decreased expression of SULT2A1 and KNG1 (FGF19 signaling repression targets) have also shown to be associated with shorter survival or development of multiple tumors, respectively (Desnoyers et al., 2008; Ho et al., 2009; French et al., 2012; Lin et al., 2019b; Raja et al., 2019). FGF19 may enhance its biological effects on HCC by activating multiple growth factor pathways. FGF19 positively regulates the expression of the EGFR ligand amphiregulin and connective tissue growth factor (CTGF) to regulate the growth and survival of HCC cells (Castillo et al., 2006; Castillo et al., 2009; Urtasun et al., 2011; Latasa et al., 2012; Uriarte et al., 2015). FGF19 increases the invasive capabilities of human HCC cell lines by promoting epithelial-mesenchymal transition (EMT) via a GSK3 $\beta$ / $\beta$-catenin pathway (Miura et al., 2012; Zhao et al., 2016). Oncogenomic screening also demonstrated that the amplification and overexpression of FGF19 occurs along with those of CCND1, known as an oncogene in HCC (Sawey et al., 2011). Non-cellautonomous activation of IL-6/STAT3 signaling is involved in FGF19-driven hepatocarcinogenesis (Zhou et al., 2017).

As a risk factor to HCC development, the overexpression of FGF19 was also detected in patients with hepatitis $\mathrm{C}$ virus cirrhosis and biliary cirrhosis. Hepatic tissue protein of FGF19 and FGFR4 is significantly correlated with histopathologic changes from fatty liver to $\mathrm{HCC}$ via regulating the epithelial cell adhesion molecule ( $\mathrm{Li}$ et al., 2016b). Ileum-derived FGF15/FGF19 could contribute to hepatocarcinogenesis in the presence of pro-tumorigenic conditions, such as chronic viral infection and alcohol consumption. FGF15 overexpression accelerates fibrosis and hepatocarcinogenesis via the upregulation of amphiregulin (AR), TGF- $\beta$, and CTGF (Uriarte et al., 2015). In a nonalcoholic steatohepatitis (NASH)-HCC mouse model, FGF15/FGFR4 signaling plays a critical role in HCC initiation and development via stimulating EMT and Wnt/ $\beta$-catenin signaling (Cui et al., 2018). The findings lend support to the pro-tumorigenic potential of FGF15/ FGF19 in the metabolic disorder microenvironment and address the importance of the role that FGF15/FGF19 play in HCC development.

Taken together, the FGF15/19-FGFR4 pathway contributes to the development of HCC. Its stimulation either through the amplification or overexpression of FGF15/19 in human HCC cells and tissues and its antitumoral effects by knocking down FGF19, FGFR4, or KLB or by the overexpression of dominantnegative FGFR4 variants in liver cancer cells in vitro and in vivo models have been shown to impact HCC cell proliferation, survival, EMT, migration, invasion, and drug resistance (French et al., 2012; Miura et al., 2012; Mellor, 2014; Repana and Ross, 2015; AlvarezSola et al., 2017; Gao et al., 2017; Cui et al., 2018; Kang et al., 2019; Kim et al., 2019a; Lin et al., 2019b; Raja et al., 2019; Weiss et al., 2019). The FGF19-FGFR4-KLB signal cascade was amplified via the activation of PI3K/AKT, RAS/RAF/MAPK, RAS/Ral/mTORC1, and GSK/ $\beta$-catenin cell signaling pathways to further mediate the development and progression of HCC (Figure 2) (Wan et al., 2016). High levels of FGF19 can be used as an independent prognostic factor for survival and may predict early recurrence of HCC after curative hepatectomy (Lin et al., 2019b). Meanwhile, targeting FGF19 by shRNA or anti-FGF19 antibody neutralization or 


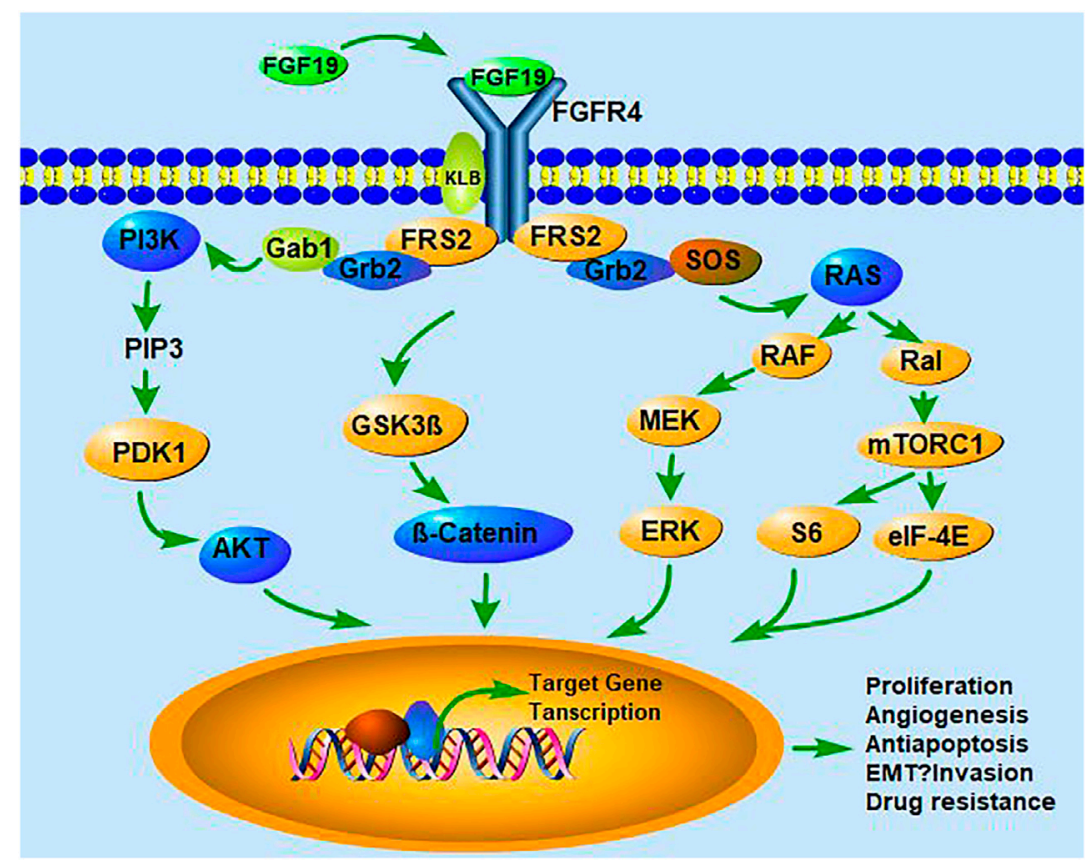

FIGURE 2 | FGF19-FGFR4 signaling pathways in HCC. FGF19, FGFR4, and KLB comprise the complex, and the activated complex stimulates a cascade of pathways, including the PI3K/AKT, RAS/RAF/MAPK, RAS/Ral/mTORC1, and GSK3 $\beta / \beta$-catenin pathway. FGF19-FGFR4-KLB ( $\beta$-klotho) signals are involved in proliferation, angiogenesis, anti-apoptosis, EMT, invasion, and drug resistance in target cells.

FGFR kinase inhibitors, LY2874455, BLU-554, and INCB06207, has been shown to inhibit the clonogenicity and tumorigenicity of FGF19 abnormal HCC (Hagel et al., 2015; Repana and Ross, 2015; Gao et al., 2017; Joshi et al., 2017; Kim et al., 2019a; Hatlen et al., 2019; Weiss et al., 2019). FGF19 could be a promising molecular target for the treatment of human HCC.

FGF21 consists of 210 amino acids in mice and 209 amino acids in humans (Motoo et al., 1993). Similar to FGF19/15 and FGF23, the effects of FGF21 are limited by the tissue-specific expression and signaling of different isoforms of FGFRs and KLB. As an inducible stress-sensing hepatokine, FGF21 expression is associated with the loss of normal functional capacity of hepatocytes due to pathogenic processes. In the normal condition, the expression of FGF21 is only detectable at a low level in the liver. However, the expression of hepatic FGF21 is increased significantly in liver diseases, such as partial hepatectomy and regeneration, hepatosteatosis, and irreversible hepatic damage from chronic hepatitis, cirrhosis, and even chemical (DEN treatment) and genetic-induced hepatocarcinogenesis (disruptions in LKB1, p53, MST1/2, SAV1, and PTEN) in mouse models and human patient samples (Yang et al., 2013a; Ye et al., 2014; Ye et al., 2016; Desai et al., 2017; Wu et al., 2017; Ritchie et al., 2020). Studies showed that FGF21 concentrations are increased in liver tissues at an early stage in human subjects and mouse model along with type 2 diabetes or steatohepatitis. However, when HCC develops, FGF21 protein levels are decreased in liver tissues. FGF21 knockout mice fed a high-fat and high-sucrose diet show significantly worse fibrosis, and $78 \%$ of mice develop HCC. By contrast, only $6 \%$ of WT mice develop
HCC. The loss of FGF21 protein in the liver is associated with hyperproliferation and aberrant p 53 and TGF- $\beta$ /Smad signaling during the development of HCC (Liu et al., 2016b). Other studies showed that forced expression of FGF21 could delay the initiation of chemically induced hepatocarcinogenesis, implying the potential anticancer properties of FGF21 (Huang et al., 2006). Related studies indicated that FGF21 is required to limit the progression of HCC carcinogenetic transformation during metabolic liver injury in diabetic subjects, which mainly function at the stage of HCC initiation (Zhang et al., 2015; Singhal et al., 2018). Moreover, $\mathrm{Wu} \mathrm{L}$ et al. found similar results in patients with $\mathrm{CHB}$. Their results showed that serum FGF21 in CHB patients exhibited a dramatic increase with the occurrence of ACLF and in CHB patients who developed HCC (Wu et al., 2017). Additionally, the high expression of FGF21, FGF19, and FGFR4 is significantly associated with better survival in a multivariate analysis with potential prognostic factors (Yoo et al., 2017). The above studies indicated that FGF21 may be a useful biomarker in monitoring tumorigenesis and evaluating the survival of patients with liver-related diseases/HCC.

\section{Other FGFS}

Besides the above FGFs, other FGFs are also involved in the development and progression of HCC. Overexpressed FGFs, including FGF4, FGF5, FGF9, and FGF22, were detected in HCC tumors but not in samples of cirrhotic tissues (Mas et al., 2007). FGF5 and FGF9 activate FGFR1c with HS in human HCC. FGF5 functions as a major target of miR-188-5p, and its restoration could reverse the inhibitory action of miR-188-5p on HCC cell proliferation and metastasis (Fang et al., 2015). Similarly, FGF9 is as 
a target of miR-140-5p, and its overexpression attenuates the effect of miR-140-5p on HCC growth and metastasis (Yang et al., 2013b).

Additionally, indirect evidence showed that FGF5 knockout mice could render $\mathrm{NASH}$, which will provide tumor microenvironment and further induce HCC (Hanaka et al., 2014). Missiaglia et al.'s study show that the FGF13 gene was significantly associated with the occurrence of liver metastasis and shorter disease-free survival (Missiaglia et al., 2010). Further study is needed to confirm the underlying relationship.

\section{FGFRS}

The FGFR family consists of FGFR1-4, which are highly conserved transmembrane tyrosine kinases receptors. FGFs transduce a series of biology activity by binding with FGFRs, HSPGs, and klotho type co-receptors. Evidence shows that FGF/FGFR signaling is involved in HCC development and progression, even in cancer treatment. Preclinical data have demonstrated that nearly $50 \%$ of HCC were directly or indirectly caused by FGF/FGFR abnormality. The signaling axis of FGF/FGFR is a tissue-specific manner based on the interaction of FGFs, FGFRs, HSPGs, and klotho type coreceptors. Consistent with the high expression levels of FGFR3 and FGFR4 in the liver, the overexpression of FGFR3 and/or FGFR4 was detected in the majority of HCC cases compared with the relatively rare upregulation of FGFR1 and/or FGFR2 (Cappellen et al., 1999; Paur et al., 2015).

FGFR4 is a human hallmark in the study of HCC disease mechanism and drug development owing to its innate advantages. The liver uniquely possesses a complete FGFR4 activating machinery, including FGFR4, FGF19, and KLB, and the specific structure of FGFR4 could be distinguished from that of other FGFRs. FGFR4 overexpression has been found in 30\% to almost $50 \%$ of HCC tissues (Desnoyers et al., 2008; French et al., 2012; Raja et al., 2019). Two different FGFR4 gene polymorphisms have been associated with increased levels of $a$-fetoprotein in HCC patients (Ho et al., 2009; Yang et al., 2012b; Sheu et al., 2015; Xie et al., 2015). FGFR4 modulates downstream pathways, such as PI3K/ AKT and RAS/RAF/MAPK, which are predominantly involved in tumor proliferation and anti-apoptosis. As discussed in the FGF19 section, the abnormality of FGF19-FGFR4-KLB is involved in HCC cell proliferation, survival, EMT, migration, and invasion (Ho et al., 2009; Yang et al., 2012b; French et al., 2012; Lin and Desnoyers, 2012; Liu et al., 2015b; Gu et al., 2015; Sheu et al., 2015; Lin et al., 2019b). FGF19 or FGFR4 functions as a potential therapeutic target for the treatment of HCC patients, which is an active topic in the field of clinical liver oncology (Zhong et al., 2014; Hagel et al., 2015; Repana and Ross, 2015; Sheu et al., 2015; Gao et al., 2017; Joshi et al., 2017; Cui et al., 2018; Kim et al., 2019a; Hatlen et al., 2019; Subbiah and Pal, 2019; Weiss et al., 2019).

The roles of other FGFRs on HCC have been explored. FGFR1 promotes HCC progression and is targeted by a series of microRNAs. Studies showed that the polymorphisms of FGFR1 are related to $\mathrm{HBV}$-related $\mathrm{HCC}$, but they do not have an independent role in tumorigenesis and progression (Wang et al., 2013; Xie et al., 2015). The high expression of FGFR2 induced by FGF7 stimulation is correlated with poor pathologic differentiation, which might increase the incidence of HCC recurrence. FGFR2 fusion mutations are reported in $13-20 \%$ of patients with intrahepatic cholangiocarcinoma (Harimoto et al., 2010; Chen et al., 2013; Jun et al., 2020). Interestingly, FGFR2-IIIb expression in HCC tissues and cell lines was lower than that in primary human hepatocytes and nontumorous tissue, and reduced expression of FGFR2IIIb induces a more aggressive growth of HCC (Amann et al., 2010). The role of FGFR2 in HCC is controversial and needs to be further determined. In cancers, FGFR3-mediating signals are often activated by manifold mechanisms, such as activating receptor mutations, translocations, altered splicing, upregulation of FGFs and/or FGFR3, and defects in negative feedback loops. The various mechanisms were reported to be associated with the development and progression of different kinds of cancers, including HCC. Bettina Grasl-Kraupp et al. found that the level of at least one of the two FGFR3 subtypes on the surface of tumor cells is significantly increased in 50\% of HCC cases. The concentration of FGFR3 in tumor tissue is positively correlated with the primary tumor size and the recurrence probability. Other previous works identified that FGFR3 overexpression is correlated with lung metastasis and angiogenesis of HCC (Paur et al., 2015; Li et al., 2016a; Liu et al., 2016a; Zhuang et al., 2018).

\section{Hepatocellular Carcinoma Therapeutics Targeted to FGFRS}

Considering the established roles of aberrant FGF/FGFR signaling in liver cancer oncogenesis, inhibitors of the FGF/FGFR signaling axis may be promising for HCC treatment, which slow or halt HCC tumor growth, target angiogenesis and metastasis, and reverse acquired resistance to anticancer agents. The development of FGFR inhibitors started from the earliest multi-target inhibitors to pan-FGFR inhibitors and then to selective FGFR4 inhibitors and irreversible FGFR4 inhibitors (French et al., 2012; Shen et al., 2013; Katoh and Nakagama, 2014; Mellor, 2014; Choi et al., 2015; Joshi et al., 2017; Ettrich and Seufferlein, 2018; Spallanzani et al., 2018; Kim et al., 2019a; Lin et al., 2019a; Doycheva and Thuluvath, 2019; Hatlen et al., 2019; Weiss et al., 2019).

Sorafenib is a landmark in the field of targeted therapy for liver cancer, which is the first approved targeted therapy for HCC and was approved by the FDA in 2007. It is an oral multi-target tyrosine kinase inhibitor with targets including CRAF, BRAF and vascular endothelial growth factor receptor (VEGFR1/2/3) and platelet-derived growth factor receptor (PDGFR) and other tyrosine kinase receptors (KIT, FLT-3, RET, RET). Moreover, for intrahepatic cholangiocarcinoma (ICC), which belong to a type of primary carcinoma of the liver, with FGFR2 gene fusion, sorafenib has a preferable clinical treatment effect (Ying et al., 2019). Sorafenib is currently suitable for the first-line treatment of inoperable or metastatic advanced HCC. Pemigatinib is the first targeted therapeutic drug for intrahepatic cholangiocarcinoma, and was approved by FDA in april 2020. According to the latest 2020 National Comprehensive Cancer Network (NCCN) guidelines (United States), if FGFR2 gene fusion or rearrangement is clinically detected in cholangiocarcinoma, the targeted drug pemigatinib can be used for treatment, and there is a favorable response (Abou-Alfa et al., 2020; Romero, 2020).

In addition, according to the 2020 Consensus for clinical application of molecular diagnosis on hepatobiliary carcinoma 
TABLE 1 | Classification and representatives of FGFR inhibitors for HCC.

\begin{tabular}{|c|c|c|c|c|c|}
\hline Classification & $\begin{array}{l}\text { Drug name } \\
\text { (alternative name) }\end{array}$ & Organization & Drug target & Phase & Clinical trial Id \\
\hline \multirow[t]{5}{*}{ Multikinase inhibitors } & Anlotinib & Chia tai-tianqing & VEGFR1/2/3, FGFR, PDGFR, KIT & Phase 3 & NCT04344158 \\
\hline & Regorafenib & Bayer & $\begin{array}{l}\text { VEGFR, FGFR, tie-1/2, PDGFR, KIT, RAF-1, BRAF, } \\
{ }^{600} \mathrm{~V} \text {, RET }\end{array}$ & Phase 2 & NCT04696055 \\
\hline & Nintedanib (BIBF1120) & Boehringer- & FGFR, VEGFR, PDGFR & Phase 1 & NCT01594125 \\
\hline & & ingelheim & & Phase 2 & NCT00987935 \\
\hline & & & & Phase 1/2 & NCT01004003 \\
\hline \multirow[t]{5}{*}{ Pan-FGFR inhibitors } & Erdafitinib & Janssen & FGFR1-4 & Phase1/2 & NCT02421185 \\
\hline & (JNJ42756493) & & & Phase $1 / 2$ & NCT02052778 \\
\hline & Futibatinib (TAS-120) & Taiho & FGFR1-4 & Phase 3 & NCT04093362 \\
\hline & AZD4547 & AstraZeneca & FGFR1-4 & Phase 2 & NCT02465060 \\
\hline & LY2874455 & Eli lilly & FGFR1-4 & Phase 1 & NCT01212107 \\
\hline FGFR4 selective reversible & H3B-6527 & H3 biomedicine & FGFR4-specific & Phase 1 & NCT02834780 \\
\hline \multirow[t]{3}{*}{ inhibitors } & Roblitinib (FGF401) & Novartis & FGFR4-specific & Phase $1 / 2$ & NCT02325739 \\
\hline & ABSK-011 & Abbisko & FGFR4-specific & Preclinical & - \\
\hline & ICP-105 & InnoCare & FGFR4-specific & Phase 1 & NCT03642834 \\
\hline \multirow{3}{*}{$\begin{array}{l}\text { FGFR4 selective irreversible } \\
\text { inhibitors }\end{array}$} & Fisogatinib (BLU-554) & CStone, blueprint & FGFR4, FGF19 & Phase $1 / 2$ & NCT04194801 \\
\hline & & & & Phase 1 & NCT02508467 \\
\hline & BLU-9931 & Blueprint & FGFR4-specific & Preclinical & - \\
\hline
\end{tabular}

(China), FGF19 gene in HCC often exhibits copy number amplification, which is closely related to the occurrence and development of HCC (Lu, 2020). The highly selective FGFR4 inhibitors, such as H3B-6527, can significantly inhibit HCC cell proliferation and benefit patients with mutations in the FGF19 signaling pathway. Moreover, FGF/FGFR gene mutation, amplification or gene fusion will cause the continuous activation of FGFR and promote the progression of many tumors. FGFR1-3 gene mutations can be detected in $11 \%$ of intrahepatic cholangiocarcinoma (ICC) (Javle et al., 2016), FGFR2 gene fusion was detected in $11-45 \%$ of cholangiocarcinoma (CCA), and the common fusion forms mainly include FGFR2-ZMYM4, FGFR2BICC1 fusion, etc (Saha et al., 2016). Furthermore, it should also pay attention to hyperprogressive disease (HPD) in tumor immunotherapy of HCC. The data shows that the incidence of HPD in tumor immunotherapy is about 10\% (Champiat et al., 2017; Ferrara et al., 2018), and the gene amplification of MDM2, MDM4, EGFR and 11q13 (including CCND1, FGF3, FGF4, FGF19) may be related to tumor immunotherapy HPD (Kato et al., 2017), the molecular mechanisms of HPD and the relative predictive biomarkers, etc., need further research.

As shown in Table 1, there are several clinical trials of FGF/ FGFR inhibitors are in progress, such as multikinase inhibitors anlotinib, regorafenib and nintedanib, pan-FGFR inhibitors erdafitinib, futibatinib, AZD4547, LY2874455. More importantly, FGF19 signaling through the FGFR4/ $\beta$-klotho receptor complex has been shown to be a key driver of growth and survival in hepatocellular carcinoma, which makes selective FGFR4 inhibition an attractive therapeutic opportunity. FGFR4 specific targeted drugs, including reversible and irreversible inhibitors, are being developed and researched. FGFR4 selective reversible inhibitors, such as H3B-6527, roblitinib (FGF401), ABSK-011 and ICP-105, bind to the FGFR4 kinase domain in a reversible covalent manner and inhibit the progression of HCC; Whereas, fisogatinib (BLU554) and BLU-9931 bind to FGFR4 in an irreversible manner.
However, most of these agents are still in early phase of clinical trials, and still have a long way to go before they can be widely used in clinical. The success of these therapies requires a comprehensive research and specific selection of patients whose tumors appear aberrant of the FGF/FGFR pathway.

\section{CONCLUSION}

The FGF/FGFR axis plays a vital role in the development and treatment of HCC. Particularly, the FGF19-FGFR4-KLB signaling system has been recognized as the main driver of hepatocarcinogenesis, and several FGFR4-specific inhibitors are being tested in clinical trials. These findings and clinical trials will be utilized to unveil the importance of the FGF/FGFR family on the HCC mechanism and speed up the development of "precise medicine" strategies for HCC treatment.

\section{AUTHOR CONTRIBUTIONS}

JL, KZ, JY, and WS reviewed and revised the article. All authors contributed to the article and approved the submitted version.

\section{FUNDING}

This work was supported by the National Natural Science Foundation of China (No: U1904133, Haijun Wang), Program for Young Key Teachers in Colleges and Universities in Henan Province (No: 2020GGJS150, Haijun Wang) and the Natural Science Foundation of Henan Province of China (No: 212300410224, Na Song), this work was also supported by National Training Programs of Innovation and Entrepreneurship for Undergraduates (202010472011, Na Song). 


\section{REFERENCES}

Abou-Alfa, G. K., Sahai, V., Hollebecque, A., Vaccaro, G., Melisi, D., Al-Rajabi, R., et al. (2020). Pemigatinib for previously treated, locally advanced or metastatic cholangiocarcinoma: a multicentre, open-label, phase 2 study. Lancet Oncol. 21 (5), 671-684. doi:10.1016/S1470-2045(20)30109-1

Agrawal, A., Parlee, S., Perez-Tilve, D., Li, P., Pan, J., Mroz, P. A., et al. (2018). Molecular elements in FGF19 and FGF21 defining KLB/FGFR activity and specificity. Mol. Metab. 13, 45-55. doi:10.1016/j.molmet.2018.05.003

Alessandri, G., Chirivi, R. G., Castellani, P., Nicoló, G., Giavazzi, R., and Zardi, L. (1998). Isolation and characterization of human tumor-derived capillary endothelial cells: role of oncofetal fibronectin. Lab. Invest. 78 (1), 127-128.

Alvarez-Sola, G., Uriarte, I., Latasa, M. U., Urtasun, R., Bárcena-Varela, M., Elizalde, M., et al. (2017). Fibroblast growth factor $15 / 19$ in hepatocarcinogenesis. Dig. Dis. 35 (3), 158-165. doi:10.1159/000450905

Amann, T., Bataille, F., Spruss, T., Dettmer, K., Wild, P., Liedtke, C., et al. (2010). Reduced expression of fibroblast growth factor receptor 2IIIb in hepatocellular carcinoma induces a more aggressive growth. Am. J. Pathol. 176 (3), 1433-1442. doi:10.2353/ajpath.2010.090356

Antunes, B. P., Vainieri, M. L., Alini, M., Monsonego-Ornan, E., Grad, S., and Yayon, A. (2020). Enhanced chondrogenic phenotype of primary bovine articular chondrocytes in Fibrin-Hyaluronan hydrogel by multi-axial mechanical loading and FGF18. Acta Biomater. 105, 170. doi:10.1016/j. actbio.2020.01.032

Asada, N., Tanaka, Y., Hayashido, Y., Toratani, S., Kan, M., Kitamoto, M., et al. (2003). Expression of fibroblast growth factor receptor genes in human hepatoma-derived cell lines. In Vitro Cel Dev Biol Anim 39 (7), 321-328. doi:10.1290/1543-706X(2003)039<0321:EOFGFR>2.0.CO;2

Baird, A., and Klagsbrun, M. (1991). The fibroblast growth factor family. Cancer Cells 3 (6), 239-243.

Beenken, A., and Mohammadi, M. (2009). The FGF family: biology, pathophysiology and therapy. Nat. Rev. Drug Discov. 8 (3), 235-253. doi:10. 1038/nrd2792

Beenken, A., and Mohammadi, M. (2012). The structural biology of the FGF19 subfamily. Adv. Exp. Med. Biol. 728, 1-24. doi:10.1007/978-1-4614-0887-1_1

Best, J., Schotten, C., Lohmann, G., Gerken, G., and Dechêne, A. (2017). Tivantinib for the treatment of hepatocellular carcinoma. Expert Opin. Pharmacother. 18 (7), 727-733. doi:10.1080/14656566.2017.1316376

Bruix, J., Sherman, M., and Practice Guidelines Committee, A. A. f. t. S. o. L. D. (2005). Management of hepatocellular carcinoma. Hepatology 42 (5), 1208-1236. doi:10.1002/hep.20933

Cappellen, D., De Oliveira, C., Ricol, D., de Medina, S., Bourdin, J., Sastre-Garau, X., et al. (1999). Frequent activating mutations of FGFR3 in human bladder and cervix carcinomas. Nat. Genet. 23 (1), 18-20. doi:10.1038/12615

Casanovas, O., Hicklin, D. J., Bergers, G., and Hanahan, D. (2005). Drug resistance by evasion of antiangiogenic targeting of VEGF signaling in late-stage pancreatic islet tumors. Cancer Cell 8 (4), 299-309. doi:10.1016/j.ccr.2005. 09.005

Castillo, J., Erroba, E., Perugorría, M. J., Santamaría, M., Lee, D. C., Prieto, J., et al. (2006). Amphiregulin contributes to the transformed phenotype of human hepatocellular carcinoma cells. Cancer Res. 66 (12), 6129-6138. doi:10.1158/ 0008-5472.CAN-06-0404

Castillo, J., Goñi, S., Latasa, M. U., Perugorría, M. J., Calvo, A., Muntané, J., et al. (2009). Amphiregulin induces the alternative splicing of p73 into its oncogenic isoform $\triangle \mathrm{Ex} 2 \mathrm{p} 73$ in human hepatocellular tumors. Gastroenterology 137 (5), 1805-1815. doi:10.1053/j.gastro.2009.07.065

Cerami, E., Gao, J., Dogrusoz, U., Gross, B. E., Sumer, S. O., Aksoy, B. A., et al. (2012). The cBio cancer genomics portal: an open platform for exploring multidimensional cancer genomics data: figure 1. Cancer Discov. 2 (5), 401-404. doi:10.1158/2159-8290.CD-12-0095

Champiat, S., Dercle, L., Ammari, S., Massard, C., Hollebecque, A., Postel-Vinay, S., et al. (2017). Hyperprogressive disease is a new pattern of progression in cancer patients treated by anti-PD-1/PD-L1. Clin. Cancer Res. 23 (8), 1920-1928. doi:10.1158/1078-0432.CCR-16-1741

Chen, G., Qiu, H., Ke, S., Hu, S., Yu, S., and Zou, S. (2013). The fibroblast growth factor receptor 2-mediated extracellular signal-regulated kinase $1 / 2$ signaling pathway plays is important in regulating excision repair cross-complementary gene 1 expression in hepatocellular carcinoma. Biomed. Rep. 1 (4), 604-608. doi:10.3892/br.2013.96

Chen, N., Ma, J., Zhao, Y., Wu, M., Yang, H., Gong, W., et al. (2016). Expression of functional recombinant human fibroblast growth factor $8 \mathrm{~b}$ and its protective effects on MPP+-lesioned PC12 cells. Appl. Microbiol. Biotechnol. 100 (2), 625-635. doi:10.1007/s00253-015-7004-4

Cheng, A.-L., Shen, Y.-C., and Zhu, A. X. (2011). Targeting fibroblast growth factor receptor signaling in hepatocellular carcinoma. Oncology 81 (5-6), 372-380. doi: $10.1159 / 000335472$

Choi, K.-J., Baik, I. H., Ye, S.-K., and Lee, Y.-H. (2015). Molecular targeted therapy for hepatocellular carcinoma: present status and future directions. Biol. Pharm. Bull. 38 (7), 986-991. doi:10.1248/bpb.b15-00231

Choi, M., Moschetta, A., Bookout, A. L., Peng, L., Umetani, M., Holmstrom, S. R., et al. (2006). Identification of a hormonal basis for gallbladder filling. Nat. Med. 12 (11), 1253-1255. doi:10.1038/nm1501

Clevers, H. (2000). Axin and hepatocellular carcinomas. Nat. Genet. 24 (3), 206-208. doi:10.1038/73396

Craig, A. J., von Felden, J., Garcia-Lezana, T., Sarcognato, S., and Villanueva, A. (2019). Tumour evolution in hepatocellular carcinoma. Nat. Rev. Gastroenterol. Hepatol. 17, 139. doi:10.1038/s41575-019-0229-4

Cui, G., Martin, R. C., Jin, H., Liu, X., Pandit, H., Zhao, H., et al. (2018). Upregulation of FGF15/19 signaling promotes hepatocellular carcinoma in the background of fatty liver. J. Exp. Clin. Cancer Res. 37 (1), 136. doi:10.1186/ s13046-018-0781-8

Desai, B. N., Singhal, G., Watanabe, M., Stevanovic, D., Lundasen, T., Fisher, f. M., et al. (2017). Fibroblast growth factor 21 (FGF21) is robustly induced by ethanol and has a protective role in ethanol associated liver injury. Mol. Metab. 6 (11), 1395-1406. doi:10.1016/j.molmet.2017.08.004

Desnoyers, L. R., Pai, R., Ferrando, R. E., Hötzel, K., Le, T., Ross, J., et al. (2008). Targeting FGF19 inhibits tumor growth in colon cancer xenograft and FGF19 transgenic hepatocellular carcinoma models. Oncogene 27 (1), 85-97. doi:10. 1038/sj.onc. 1210623

Ding, X., Boney-Montoya, J., Owen, B. M., Bookout, A. L., Coate, K. C., Mangelsdorf, D. J., et al. (2012). $\beta$ Klotho is required for fibroblast growth factor 21 effects on growth and metabolism. Cel Metab. 16 (3), 387-393. doi:10. 1016/j.cmet.2012.08.002

Doycheva, I., and Thuluvath, P. J. (2019). Systemic therapy for advanced hepatocellular carcinoma: an update of a rapidly evolving field. J. Clin. Exp. Hepatol. 9 (5), 588-596. doi:10.1016/j.jceh.2019.07.012

El-Gendi, S., Abdelzaher, E., Mostafa, M. F., and Sheasha, G. A. (2016). FGF18 as a potential biomarker in serous and mucinous ovarian tumors. Tumor Biol. 37 (3), 3173-3183. doi:10.1007/s13277-015-4129-0

Elzi, D. J., Song, M., Blackman, B., Weintraub, S. T., López-Terrada, D., Chen, Y., et al. (2016). FGF19 functions as autocrine growth factor for hepatoblastoma. Genes Cancer 7 (3-4), 125-135. doi:10.18632/genesandcancer.101

Ersoy, F. F. (2014). A short story of Klotho and FGF23: a deuce of dark side or the savior?. Int. Urol. Nephrol. 46 (3), 577-581. doi:10.1007/s11255-013-0536-6

Eswarakumar, V. P., Lax, I., and Schlessinger, J. (2005). Cellular signaling by fibroblast growth factor receptors. Cytokine Growth Factor. Rev. 16 (2), 139-149. doi: doi:10.1016/j.cytogfr.2005.01.001

Ettrich, T. J., and Seufferlein, T. (2018). Regorafenib. Regorafenib. Recent Results Cancer Res. 211, 45-56. doi:10.1007/978-3-319-91442-8_3

Fang, F., Chang, R.-m., Yu, L., Lei, X., Xiao, S., Yang, H., et al. (2015). MicroRNA188-5p suppresses tumor cell proliferation and metastasis by directly targeting FGF5 in hepatocellular carcinoma. J. Hepatol. 63 (4), 874-885. doi:10.1016/j. jhep.2015.05.008

Ferrara, R., Mezquita, L., Texier, M., Lahmar, J., Audigier-Valette, C., Tessonnier, L., et al. (2018). Hyperprogressive disease in patients with advanced non-small cell lung cancer treated with PD-1/PD-L1 inhibitors or with single-agent chemotherapy. JAMA Oncol. 4 (11), 1543-1552. doi:10.1001/jamaoncol. 2018.3676

Flannery, C. A., Fleming, A. G., Choe, G. H., Naqvi, H., Zhang, M., Sharma, A., et al. (2016). Endometrial cancer-associated FGF18 expression is reduced by bazedoxifene in human endometrial stromal cells in vitro and in murine endometrium. Endocrinology 157 (10), 3699-3708. doi:10.1210/en.20161233

Fon Tacer, K., Bookout, A. L., Ding, X., Kurosu, H., John, G. B., Wang, L., et al. (2010). Research resource: comprehensive expression atlas of the fibroblast 
growth factor system in adult mouse. Mol. Endocrinol. 24 (10), 2050-2064. doi:10.1210/me.2010-0142

French, D. M., Lin, B. C., Wang, M., Adams, C., Shek, T., Hötzel, K., et al. (2012). Targeting FGFR4 inhibits hepatocellular carcinoma in preclinical mouse models. PLoS One 7 (5), e36713, doi:10.1371/journal.pone.0036713

Fukumoto, S. (2019). FGF23 and bone and mineral metabolism. Handb Exp. Pharmacol., 281. doi:10.1007/164_2019_330

Gambarini, A. G., and Armelin, H. A. (1982). Purification and partial characterization of an acidic fibroblast growth factor from bovine pituitary. J. Biol. Chem. 257 (16), 9692-9697. doi:10.1016/s0021-9258(18)34128-0

Gao, J., Aksoy, B. A., Dogrusoz, U., Dresdner, G., Gross, B., Sumer, S. O., et al. (2013). Integrative analysis of complex cancer genomics and clinical profiles using the cBioPortal. Sci. Signaling 6 (269), pl1. doi:10.1126/scisignal.2004088

Gao, L., Wang, X., Tang, Y., Huang, S., Hu, C.-A. A., and Teng, Y. (2017). FGF19/ FGFR4 signaling contributes to the resistance of hepatocellular carcinoma to sorafenib. J. Exp. Clin. Cancer Res. 36 (1), 8. doi:10.1186/s13046-016-0478-9

Gauglhofer, C., Sagmeister, S., Schrottmaier, W., Fischer, C., Rodgarkia-Dara, C., Mohr, T., et al. (2011). Up-regulation of the fibroblast growth factor 8 subfamily in human hepatocellular carcinoma for cell survival and neoangiogenesis. Hepatology 53 (3), 854-864. doi: doi:10.1002/hep.24099

Goetz, R., Beenken, A., Ibrahimi, O. A., Kalinina, J., Olsen, S. K., Eliseenkova, A. V., et al. (2007). Molecular insights into the klotho-dependent, endocrine mode of action of fibroblast growth factor 19 subfamily members. Mcb 27 (9), 3417-3428. doi:10.1128/MCB.02249-06

Gospodarowicz, D., Jones, K. L., and Sato, G. (1974). Purification of a growth factor for ovarian cells from bovine pituitary glands. Proc. Natl. Acad. Sci. 71 (6), 2295-2299. doi:10.1073/pnas.71.6.2295

Gospodarowicz, D. (1975). Purification of a fibroblast growth factor from bovine pituitary. J. Biol. Chem. 250 (7), 2515-2520. doi:10.1016/s0021-9258(19) $41631-1$

Gu, Q., Zhang, B., Sun, H., Xu, Q., Tan, Y., Wang, G., et al. (2015). Genomic characterization of a large panel of patient-derived hepatocellular carcinoma xenograft tumor models for preclinical development. Oncotarget 6 (24), 20160-20176. doi:10.18632/oncotarget.3969

Guo, P., Wang, Y., Dai, C., Tao, C., Wu, F., Xie, X., et al. (2018). Ribosomal protein S15a promotes tumor angiogenesis via enhancing $\mathrm{Wnt} / \beta$-catenin-induced FGF18 expression in hepatocellular carcinoma. Oncogene 37 (9), 1220-1236. doi:10.1038/s41388-017-0017-y

Hagan, A. S., Zhang, B., and Ornitz, D. M. (2020). Identification of a FGF18expressing alveolar myofibroblast that is developmentally cleared during alveologenesis. Development 147 (2), dev181032. doi:10.1242/dev.181032

Hagel, M., Miduturu, C., Sheets, M., Rubin, N., Weng, W., Stransky, N., et al. (2015). First selective small molecule inhibitor of FGFR4 for the treatment of hepatocellular carcinomas with an activated FGFR4 signaling pathway. Cancer Discov. 5 (4), 424-437. doi:10.1158/2159-8290.CD-14-1029

Hajihosseini, M. K., and Heath, J. K. (2002). Expression patterns of fibroblast growth factors-18 and -20 in mouse embryos is suggestive of novel roles in calvarial and limb development. Mech. Dev. 113 (1), 79-83. doi:10.1016/s09254773(01)00656-6

Hanaka, H., Hamada, T., Ito, M., Nakashima, H., Tomita, K., Seki, S., et al. (2014). Fibroblast growth factor-5 participates in the progression of hepatic fibrosis. Exp. Anim. 63 (1), 85-92. doi:10.1538/expanim.63.85

Haque, T., Nakada, S., and Hamdy, R. C. (2007). A review of FGF18: its expression, signaling pathways and possible functions during embryogenesis and post-natal development. Histol. Histopathol 22 (1), 97-105. doi:10.14670/HH-22.97

Harimoto, N., Taguchi, K., Shirabe, K., Adachi, E., Sakaguchi, Y., Toh, Y., et al. (2010). The significance of fibroblast growth factor receptor 2 expression in differentiation of hepatocellular carcinoma. Oncology 78 (5-6), 361-368. doi:10. $1159 / 000320463$

Hatlen, M. A., Schmidt-Kittler, O., Sherwin, C. A., Rozsahegyi, E., Rubin, N., Sheets, M. P., et al. (2019). Acquired on-target clinical resistance validates FGFR4 as a driver of hepatocellular carcinoma. Cancer Discov. 9 (12), CD-19. doi:10.1158/2159-8290.CD-19-0367

Ho, H. K., Pok, S., Streit, S., Ruhe, J. E., Hart, S., Lim, K. S., et al. (2009). Fibroblast growth factor receptor 4 regulates proliferation, anti-apoptosis and alphafetoprotein secretion during hepatocellular carcinoma progression and represents a potential target for therapeutic intervention. J. Hepatol. 50 (1), 118-127. doi:10.1016/j.jhep.2008.08.015
Hu, M. C.-T., Qiu, W. R., Wang, Y.-p., Hill, D., Ring, B. D., Scully, S., et al. (1998). FGF-18, a novel member of the fibroblast growth factor family, stimulates hepatic and intestinal proliferation. Mol. Cel. Biol. 18 (10), 6063-6074. doi:10. $1128 / \mathrm{mcb} .18 .10 .6063$

Huang, X., Yu, C., Jin, C., Yang, C., Xie, R., Cao, D., et al. (2006). Forced expression of hepatocyte-specific fibroblast growth factor 21 delays initiation of chemically induced hepatocarcinogenesis. Mol. Carcinog. 45 (12), 934-942. doi:10.1002/ mc.20241

Hung, I. H., Schoenwolf, G. C., Lewandoski, M., and Ornitz, D. M. (2016). A combined series of Fgf9 and Fgf18 mutant alleles identifies unique and redundant roles in skeletal development. Dev. Biol. 411 (1), 72-84. doi:10. 1016/j.ydbio.2016.01.008

Inagaki, T., Dutchak, P., Zhao, G., Ding, X., Gautron, L., Parameswara, V., et al. (2007). Endocrine regulation of the fasting response by ppara-mediated induction of fibroblast growth factor 21. Cel Metab. 5 (6), 415-425. doi:10. 1016/j.cmet.2007.05.003

Itoh, N. (2010). Hormone-like (endocrine) Fgfs: their evolutionary history and roles in development, metabolism, and disease. Cell Tissue Res 342 (1), 1-11. doi:10.1007/s00441-010-1024-2

Itoh, N., Nakayama, Y., and Konishi, M. (2016). Roles of FGFs as paracrine or endocrine signals in liver development, health, and disease. Front. Cel Dev. Biol. 4, 30. doi:10.3389/fcell.2016.00030

Itoh, N., and Ornitz, D. M. (2004). Evolution of the fgf and fgfr gene families. Trends Genet. 20 (11), 563-569. doi:10.1016/j.tig.2004.08.007

Itoh, N., and Ornitz, D. M. (2011). Fibroblast growth factors: from molecular evolution to roles in development, metabolism and disease. J. Biochem. 149 (2), 121-130. doi:10.1093/jb/mvq121

Itoh, N., and Ornitz, D. M. (2008). Functional evolutionary history of the mouseFgf gene family. Dev. Dyn. 237 (1), 18-27. doi:10.1002/dvdy.21388

Itoh, N. (2007). The Fgf families in humans, mice, and zebrafish: their evolutional processes and roles in development, metabolism, and disease. Biol. Pharm. Bull. 30 (10), 1819-1825. doi:10.1248/bpb.30.1819

Javle, M., Bekaii-Saab, T., Jain, A., Wang, Y., Kelley, R. K., Wang, K., et al. (2016). Biliary cancer: utility of next-generation sequencing for clinical management. Cancer 122 (24), 3838-3847. doi:10.1002/cncr.30254

Jin-no, K., Tanimizu, M., Hyodo, I., Kurimoto, F., and Yamashita, T. (1997). Plasma level of basic fibroblast growth factor increases with progression of chronic liver disease. J. Gastroenterol. 32 (1), 119-121. doi:10.1007/ bf01213308

Jomrich, G., Hudec, X., Harpain, F., Winkler, D., Timelthaler, G., Mohr, T., et al.(2019). Expression of FGF8, FGF18, and FGFR4 in gastroesophageal adenocarcinomas. Cells 8 (9), 1092. doi:10.3390/cells8091092

Joshi, J. J., Coffey, H., Corcoran, E., Tsai, J., Huang, C.-L., Ichikawa, K., et al. (2017). H3B-6527 is a potent and selective inhibitor of FGFR4 in FGF19-driven hepatocellular carcinoma. Cancer Res. 77 (24), 6999-7013. doi:10.1158/00085472.CAN-17-1865

Jun, B. G., Lee, W. C., Jang, J. Y., Jeong, S. W., Chang, Y., Lee, S. H., et al. (2020). Relation of fibroblast growth factor receptor 2 expression to hepatocellular carcinoma recurrence after liver resection. PLoS One 15 (1), e0227440. doi:10. 1371/journal.pone. 0227440

Kang, H. J., Haq, F., Sung, C. O., Choi, J., Hong, S.-M., Eo, S.-H., et al. (2019). Characterization of hepatocellular carcinoma patients with FGF19 amplification assessed by fluorescence in situ hybridization: a large cohort study. Liver Cancer 8 (1), 12-23. doi:10.1159/000488541

Kato, S., Goodman, A., Walavalkar, V., Barkauskas, D. A., Sharabi, A., and Kurzrock, R. (2017). Hyperprogressors after immunotherapy: analysis of genomic alterations associated with accelerated growth rate. Clin. Cancer Res. 23 (15), 4242-4250. doi:10.1158/1078-0432.CCR-16-3133

Katoh, M. (2016). FGFR inhibitors: effects on cancer cells, tumor microenvironment and whole-body homeostasis (Review). Int. J. Mol. Med. 38 (1), 3-15. doi:10.3892/ijmm.2016.2620

Katoh, M., and Nakagama, H. (2014). FGF receptors: cancer biology and therapeutics. Med. Res. Rev. 34 (2), 280-300. doi:10.1002/med.21288

Kharitonenkov, A., Dunbar, J. D., Bina, H. A., Bright, S., Moyers, J. S., Zhang, C., et al. (2008). FGF-21/FGF-21 receptor interaction and activation is determined by ßKlotho. J. Cel. Physiol. 215 (1), 1-7. doi:10.1002/jcp.21357

Kim, R. D., Sarker, D., Meyer, T., Yau, T., Macarulla, T., Park, J.-W., et al. (2019a). First-in-Human phase I study of fisogatinib (BLU-554) validates aberrant 
FGF19 signaling as a driver event in hepatocellular carcinoma. Cancer Discov. 9 (12), 1696-1707. doi:10.1158/2159-8290.CD-19-0555

Kim, S. S., Eun, J. W., Cho, H. J., Lee, H.-Y., Seo, C. W., Noh, C. K., et al. (2019b). Effect of fibroblast growth factor-2 and its receptor gene polymorphisms on the survival of patients with hepatitis B virus-associated hepatocellular carcinoma. Anticancer Res. 39 (4), 2217-2226. doi:10.21873/anticanres.13337

Kin, M., Sata, M., Ueno, T., Torimura, T., Inuzuka, S., Tsuji, R., et al. (1997). Basic fibroblast growth factor regulates proliferation and motility of human hepatoma cells by an autocrine mechanism. J. Hepatol. 27 (4), 677-687. doi:10.1016/s0168-8278(97)80085-2

Kir, S., Kliewer, S. A., and Mangelsdorf, D. J. (2011). Roles of FGF19 in liver metabolism. Cold Spring Harbor Symposia Quantitative Biol. 76, 139-144. doi:10.1101/sqb.2011.76.010710

Koneczny, I., Schulenburg, A., Hudec, X., Knöfler, M., Holzmann, K., Piazza, G., et al. (2015). Autocrine fibroblast growth factor 18 signaling mediates Wntdependent stimulation of CD44-positive human colorectal adenoma cells. Mol. Carcinog. 54 (9), 789-799. doi:10.1002/mc.22146

Kulbe, H., Otto, R., Darb-Esfahani, S., Lammert, H., Abobaker, S., Welsch, G., et al. (2019). Discovery and validation of novel biomarkers for detection of epithelial ovarian cancer. Cells 8 (7), 713. doi:10.3390/cells8070713

Kuro-o, M. (2012). Klotho and $\beta$ Klotho. Adv. Exp. Med. Biol. 728, 25-40. doi:10. 1007/978-1-4614-0887-1_2

Kurosu, H., Choi, M., Ogawa, Y., Dickson, A. S., Goetz, R., Eliseenkova, A. V., et al. (2007). Tissue-specific expression of $\beta$ Klotho and fibroblast growth factor (FGF) receptor isoforms determines metabolic activity of FGF19 and FGF21. J. Biol. Chem. 282 (37), 26687-26695. doi:10.1074/jbc.M704165200

Latasa, M. U., Salis, F., Urtasun, R., Garcia-Irigoyen, O., Elizalde, M., Uriarte, I., et al. (2012). Regulation of amphiregulin gene expression by $\beta$-catenin signaling in human hepatocellular carcinoma cells: a novel crosstalk between FGF19 and the EGFR system. PLoS One 7 (12), e52711. doi:10.1371/journal.pone.0052711

Lemmon, S. K., and Bradshaw, R. A. (1983). Purification and partial characterization of bovine pituitary fibroblast growth factor. J. Cel. Biochem. 21 (3), 195-208. doi:10.1002/jcb.240210302

Li, K., Shen, B., Cheng, X., Ma, D., Jing, X., Liu, X., et al. (2016a). Phenotypic and signaling consequences of a novel aberrantly spliced transcript FGF receptor-3 in hepatocellular carcinoma. Cancer Res. 76 (14), 4205-4215. doi:10.1158/00085472.CAN-15-3385

Li, Y., Zhang, W., Doughtie, A., Cui, G., Li, X., Pandit, H., et al. (2016b). Upregulation of fibroblast growth factor 19 and its receptor associates with progression from fatty liver to hepatocellular carcinoma. Oncotarget 7 (32), 52329-52339. doi:10.18632/oncotarget. 10750

Lin, B. C., and Desnoyers, L. R. (2012). FGF19 and cancer. Adv. Exp. Med. Biol. 728, 183-194. doi:10.1007/978-1-4614-0887-1_12

Lin, B. C., Wang, M., Blackmore, C., and Desnoyers, L. R. (2007). Liver-specific activities of FGF19 require Klotho beta. J. Biol. Chem. 282 (37), 27277-27284. doi:10.1074/jbc.M704244200

Lin, X., Yosaatmadja, Y., Kalyukina, M., Middleditch, M. J., Zhang, Z., Lu, X., et al. (2019a). Rotational freedom, steric hindrance, and protein dynamics explain BLU554 selectivity for the hinge cysteine of FGFR4. ACS Med. Chem. Lett. 10 (8), 1180-1186. doi:10.1021/acsmedchemlett.9b00196

Lin, Z. Z., Hsu, C., Jeng, Y. M., Hu, F. C., Pan, H. W., Wu, Y. M., et al. (2019b). Klotho-beta and fibroblast growth factor 19 expression correlates with early recurrence of resectable hepatocellular carcinoma. Liver Int. 39 (9), 1682-1691. doi:10.1111/liv.14055

Linscott, M. L., and Chung, W. C. J. (2016). Fibroblast growth factor 8 expression in GT1-7 GnRH-secreting neurons is androgen-independent, but can Be upregulated by the inhibition of DNA methyltransferases. Front. Cel Dev. Biol. 4, 34. doi: $10.3389 / \mathrm{fcell} .2016 .00034$

Liu, R., Huang, S., Lei, Y., Zhang, T., Wang, K., Liu, B., et al. (2015a). FGF8 promotes colorectal cancer growth and metastasis by activating YAP1. Oncotarget 6 (2), 935-952. doi:10.18632/oncotarget.2822

Liu, W.-Y., Xie, D.-M., Zhu, G.-Q., Huang, G.-Q., Lin, Y.-Q., Wang, L.-R., et al. (2015b). Targeting fibroblast growth factor 19 in liver disease: a potential biomarker and therapeutic target. Expert Opin. Ther. Targets 19 (5), 675-685. doi:10.1517/14728222.2014.997711

Liu, X., Zhang, P., Martin, R. C., Cui, G., Wang, G., Tan, Y., et al. (2016b). Lack of fibroblast growth factor 21 accelerates metabolic liver injury characterized by steatohepatities in mice. Am. J. Cancer Res. 6 (5), 1011-1025.
Liu, X., Jing, X., Cheng, X., Ma, D., Jin, Z., Yang, W., et al. (2016a). FGFR3 promotes angiogenesis-dependent metastasis of hepatocellular carcinoma via facilitating MCP-1-mediated vascular formation. Med. Oncol. 33 (5), 46. doi:10. 1007/s12032-016-0761-9

Liu, Z., Lavine, K. J., Hung, I. H., and Ornitz, D. M. (2007). FGF18 is required for early chondrocyte proliferation, hypertrophy and vascular invasion of the growth plate. Dev. Biol. 302 (1), 80-91. doi:10.1016/j.ydbio.2006.08.071

Llovet, J. M., Villanueva, A., Lachenmayer, A., and Finn, R. S. (2015). Erratum: advances in targeted therapies for hepatocellular carcinoma in the genomic era. Nat. Rev. Clin. Oncol. 12 (8), 436. doi:10.1038/nrclinonc.2015.121

Lu, X., Chen, H., Patterson, A. V., Smaill, J. B., and Ding, K. (2019). Fibroblast growth factor receptor 4 (FGFR4) selective inhibitors as hepatocellular carcinoma therapy: advances and prospects. J. Med. Chem. 62 (6), 2905-2915. doi:10.1021/acs.jmedchem.8b01531

Lu, Y., Zhao, H., Cheng, J., and Ji, J. (2020). Consensus for clinical application of molecular diagnosis on hepatobiliary carcinoma. J. Clin. Hepatol. 36 (7), 1482-1488. doi:10.3969/j.issn.1001-5256.2020.07.008

Luo, Y., Ye, S., Chen, X., Gong, F., Lu, W., and Li, X. (2017). Rush to the fire: FGF21 extinguishes metabolic stress, metaflammation and tissue damage. Cytokine Growth Factor. Rev. 38, 59-65. doi:10.1016/j.cytogfr.2017.08.001

Maeda, T., Kanzaki, H., Chiba, T., Ao, J., Kanayama, K., Maruta, S., et al. (2019). Serum fibroblast growth factor 19 serves as a potential novel biomarker for hepatocellular carcinoma. BMC Cancer 19 (1), 1088. doi:10.1186/s12885-0196322-9

Mas, V. R., Maluf, D. G., Archer, K. J., Yanek, K. C., and Fisher, R. A. (2007). Angiogenesis soluble factors as hepatocellular carcinoma noninvasive markers for monitoring hepatitis C virus cirrhotic patients awaiting liver transplantation. Transplantation 84 (10), 1262-1271. doi:10.1097/01.tp. 0000287596.91520.1a

Mellor, H. R. (2014). Targeted inhibition of the FGF19-FGFR4 pathway in hepatocellular carcinoma; translational safety considerations. Liver Int. 34 (6), e1-e9. doi:10.1111/liv.12462

Midorikawa, Y., Ishikawa, S., Iwanari, H., Imamura, T., Sakamoto, H., Miyazono, K., et al. (2003). Glypican-3, overexpressed in hepatocellular carcinoma, modulates FGF2 and BMP-7 signaling. Int. J. Cancer 103 (4), 455-465. doi:10.1002/ijc.10856

Mikhaylenko, D. S., Alekseev, B. Y., Zaletaev, D. V., Goncharova, R. I., and Nemtsova, M. V. (2018). Structural alterations in human fibroblast growth factor receptors in carcinogenesis. Biochem. Mosc. 83 (8), 930-943. doi:10.1134/ S0006297918080059

Missiaglia, E., Dalai, I., Barbi, S., Beghelli, S., Falconi, M., della Peruta, M., et al. (2010). Pancreatic endocrine tumors: expression profiling evidences a role for AKT-mTOR pathway. Jco 28 (2), 245-255. doi:10.1200/JCO.2008.21.5988

Miura, S., Mitsuhashi, N., Shimizu, H., Kimura, F., Yoshidome, H., Otsuka, M., et al. (2012). Fibroblast growth factor 19 expression correlates with tumor progression and poorer prognosis of hepatocellular carcinoma. BMC Cancer 12, 56. doi:10.1186/1471-2407-12-56

Moeini, A., Cornellà, H., and Villanueva, A. (2012). Emerging signaling pathways in hepatocellular carcinoma. Liver Cancer 1 (2), 83-93. doi:10.1159/000342405

Motoo, Y., Sawabu, N., Yamaguchi, Y., Terada, T., and Nakanuma, Y. (1993). Sinusoidal capillarization of human hepatocellular carcinoma: possible promotion by fibroblast growth factor. Oncology 50 (4), 270-274. doi:10. $1159 / 000227194$

Naugler, W. E., Tarlow, B. D., Fedorov, L. M., Taylor, M., Pelz, C., Li, B., et al. (2015). Fibroblast growth factor signaling controls liver size in mice with humanized livers. Gastroenterology 149 (3), 728-740. doi:10.1053/j.gastro.2015. 05.043

Nicholes, K., Guillet, S., Tomlinson, E., Hillan, K., Wright, B., Frantz, G. D., et al. (2002). A mouse model of hepatocellular carcinoma. Am. J. Pathol. 160 (6), 2295-2307. doi:10.1016/S0002-9440(10)61177-7

Ohbayashi, N., Hoshikawa, M., Kimura, S., Yamasaki, M., Fukui, S., and Itoh, N. (1998). Structure and expression of the mRNA encoding a novel fibroblast growth factor, FGF-18. J. Biol. Chem. 273 (29), 18161-18164. doi:10.1074/jbc. 273.29.18161

Ornitz, D. M., and Itoh, N. (2015). The fibroblast growth factor signaling pathway. Wires Dev. Biol. 4 (3), 215-266. doi:10.1002/wdev.176

Paur, J., Nika, L., Maier, C., Moscu-Gregor, A., Kostka, J., Huber, D., et al. (2015). Fibroblast growth factor receptor 3 isoforms: novel therapeutic targets for 
hepatocellular carcinoma?. Hepatology 62 (6), 1767-1778. doi:10.1002/hep. 28023

Pereira, R. C., Salusky, I. B., Bowen, R. E., Freymiller, E. G., and Wesseling-Perry, K. (2019). Vitamin D sterols increase FGF23 expression by stimulating osteoblast and osteocyte maturation in CKD bone. Bone 127, 626-634. doi:10.1016/j.bone. 2019.07.026

Poon, R. T., Lau, C. P., Cheung, S. T., Yu, W. C., and Fan, S. T. (2003). Quantitative correlation of serum levels and tumor expression of vascular endothelial growth factor in patients with hepatocellular carcinoma. Cancer Res. 63 (12), 3121-3126.

Poon, R. T.-P., Ng, I. O.-L., Lau, C., Yu, W.-C., Fan, S.-T., and Wong, J. (2001). Correlation of serum basic fibroblast growth factor levels with clinicopathologic features and postoperative recurrence in hepatocellular carcinoma. Am. J. Surg. 182 (3), 298-304. doi:10.1016/s0002-9610(01)00708-5

Raja, A., Park, I., Haq, F., and Ahn, S.-M. (2019). FGF19-FGFR4 signaling in hepatocellular carcinoma. Cells 8 (6), 536. doi:10.3390/cells8060536

Reinhold, M. I., and Naski, M. C. (2007). Direct interactions of Runx2 and canonical Wnt signaling induce FGF18. J. Biol. Chem. 282 (6), 3653-3663. doi:10.1074/jbc.M608995200

Repana, D., and Ross, P. (2015). Targeting FGF19/FGFR4 pathway: a novel therapeutic strategy for hepatocellular carcinoma. Diseases 3 (4), 294-305. doi:10.3390/diseases3040294

Ritchie, M., Hanouneh, I. A., Noureddin, M., Rolph, T., and Alkhouri, N. (2020). Fibroblast growth factor (FGF)-21 based therapies: a magic bullet for nonalcoholic fatty liver disease (NAFLD)?. Expert Opin. Investig. Drugs 29 (2), 197-204. doi:10.1080/13543784.2020.1718104

Romero, D. (2020). Benefit from pemigatinib in cholangiocarcinoma. Nat. Rev. Clin. Oncol. 17 (6), 337. doi:10.1038/s41571-020-0369-z

Sagmeister, S., Eisenbauer, M., Pirker, C., Mohr, T., Holzmann, K., Zwickl, H., et al. (2008). New cellular tools reveal complex epithelial-mesenchymal interactions in hepatocarcinogenesis. Br. J. Cancer 99 (1), 151-159. doi:10.1038/sj.bjc. 6604440

Saha, S. K., Zhu, A. X., Fuchs, C. S., and Brooks, G. A. (2016). Forty-year trends in cholangiocarcinoma incidence in the U.S.: intrahepatic disease on the rise. The Oncologist 21 (5), 594-599. doi:10.1634/theoncologist.2015-0446

Sandhu, D. S., Baichoo, E., and Roberts, L. R. (2014). Fibroblast growth factor signaling in liver carcinogenesis. Hepatology 59 (3), 1166-1173. doi:10.1002/ hep. 26679

Sawey, E. T., Chanrion, M., Cai, C., Wu, G., Zhang, J., Zender, L., et al. (2011). Identification of a therapeutic strategy targeting amplified FGF19 in liver cancer by Oncogenomic screening. Cancer Cell 19 (3), 347-358. doi:10.1016/j.ccr.2011. 01.040

Schumann, G., Liu, C., O'Reilly, P., Gao, H., Song, P., Xu, B., et al. (2016). KLB is associated with alcohol drinking, and its gene product $\beta$-Klotho is necessary for FGF21 regulation of alcohol preference. Proc. Natl. Acad. Sci. USA 113 (50), 14372-14377. doi:10.1073/pnas.1611243113

Shen, Y.-C., Lin, Z.-Z., Hsu, C.-H., Hsu, C., Shao, Y.-Y., and Cheng, A.-L. (2013). Clinical trials in hepatocellular carcinoma: an update. Liver Cancer 2 (3-4), 345-364. doi:10.1159/000343850

Sheu, M.-J., Hsieh, M.-J., Chiang, W.-L., Yang, S.-F., Lee, H.-L., Lee, L.-M., et al. (2015). Fibroblast growth factor receptor 4 polymorphism is associated with liver cirrhosis in hepatocarcinoma. PLoS One 10 (4), e0122961, doi:10.1371/ journal.pone.0122961

Shimada, T., Kakitani, M., Yamazaki, Y., Hasegawa, H., Takeuchi, Y., Fujita, T., et al. (2004). Targeted ablation of Fgf23 demonstrates an essential physiological role of FGF23 in phosphate and vitamin D metabolism. J. Clin. Invest. 113 (4), 561-568. doi:10.1172/JCI19081

Shimokawa, T., Furukawa, Y., Sakai, M., Li, M., Miwa, N., Lin, Y. M., et al. (2003). Involvement of the FGF18 gene in colorectal carcinogenesis, as a novel downstream target of the beta-catenin/T-cell factor complex. Cancer Res. 63 (19), 6116-6120.

Singhal, G., Kumar, G., Chan, S., Fisher, f. M., Ma, Y., Vardeh, H. G., et al. (2018). Deficiency of fibroblast growth factor 21 (FGF21) promotes hepatocellular carcinoma (HCC) in mice on a long term obesogenic diet. Mol. Metab. 13, 56-66. doi:10.1016/j.molmet.2018.03.002

Sonvilla, G., Allerstorfer, S., Stattner, S., Karner, J., Klimpfinger, M., Fischer, H., et al. (2008). FGF18 in colorectal tumour cells: autocrine and paracrine effects. Carcinogenesis 29 (1), 15-24. doi:10.1093/carcin/bgm202
Spallanzani, A., Orsi, G., Andrikou, K., Gelsomino, F., Rimini, M., Riggi, L., et al. (2018). Lenvatinib as a therapy for unresectable hepatocellular carcinoma. Expert Rev. Anticancer Ther. 18 (11), 1069-1076. doi:10.1080/14737140.2018. 1524297

Subbiah, V., and Pal, S. K. (2019). Precision oncology for hepatocellular cancer: slivering the liver by FGF19-FGFR4-KLB pathway inhibition. Cancer Discov. 9 (12), 1646-1649. doi:10.1158/2159-8290.CD-19-1156

Sung, H., Ferlay, J., Siegel, R. L., Laversanne, M., Soerjomataram, I., Jemal, A., et al. (2021). Global cancer statistics 2020: GLOBOCAN estimates of incidence and mortality worldwide for 36 cancers in 185 countries. CA A. Cancer J. Clin.. doi: $10.3322 /$ caac. 21660

Tang, Z., Kang, B., Li, C., Chen, T., and Zhang, Z. (2019). GEPIA2: an enhanced web server for large-scale expression profiling and interactive analysis. Nucleic Acids Res. 47 (W1), W556-W560. doi:10.1093/nar/gkz430

Tang, Z., Li, C., Kang, B., Gao, G., Li, C., and Zhang, Z. (2017). GEPIA: a web server for cancer and normal gene expression profiling and interactive analyses. Nucleic Acids Res. 45 (W1), W98-W102. doi:10.1093/nar/gkx247

Touat, M., Ileana, E., Postel-Vinay, S., André, F., and Soria, J.-C. (2015). Targeting FGFR signaling in cancer. Clin. Cancer Res. 21 (12), 2684-2694. doi:10.1158/ 1078-0432.CCR-14-2329

Tulin, S., and Stathopoulos, A. (2010). Extending the family table: insights from beyond vertebrates into the regulation of embryonic development by FGFs. Birth Defects Res. C: Embryo Today Rev. 90 (3), 214-227. doi:10.1002/bdrc. 20182

Turner, N., and Grose, R. (2010). Fibroblast growth factor signalling: from development to cancer. Nat. Rev. Cancer 10 (2), 116-129. doi:10.1038/ nrc2780

Urakawa, I., Yamazaki, Y., Shimada, T., Iijima, K., Hasegawa, H., Okawa, K., et al. (2006). Klotho converts canonical FGF receptor into a specific receptor for FGF23. Nature 444 (7120), 770-774. doi:10.1038/nature05315

Uriarte, I., Latasa, M. U., Carotti, S., Fernandez-Barrena, M. G., Garcia-Irigoyen, O., Elizalde, M., et al. (2015). Ileal FGF15 contributes to fibrosis-associated hepatocellular carcinoma development. Int. J. Cancer 136 (10), 2469-2475. doi:10.1002/ijc.29287

Urtasun, R., Latasa, M. U., Demartis, M. I., Balzani, S., Goñi, S., Garcia-Irigoyen, O., et al. (2011). Connective tissue growth factor autocriny in human hepatocellular carcinoma: oncogenic role and regulation by epidermal growth factor receptor/ yes-associated protein-mediated activation. Hepatology 54 (6), 2149-2158. doi:10.1002/hep. 24587

Wan, Z. Y., Tian, J. S., Tan, H. W. S., Chow, A. L., Sim, A. Y. L., Ban, K. H. K., et al. (2016). Mechanistic target of rapamycin complex 1 is an essential mediator of metabolic and mitogenic effects of fibroblast growth factor 19 in hepatoma cells. Hepatology 64 (4), 1289-1301. doi:10.1002/hep.28639

Wang, J., Li, J., Wang, X., Zheng, C., and Ma, W. (2013). Downregulation of microRNA-214 and overexpression of FGFR-1 contribute to hepatocellular carcinoma metastasis. Biochem. Biophysical Res. Commun. 439 (1), 47-53. doi:10.1016/j.bbrc.2013.08.032

Wang, J., Liu, S., Li, J., and Yi, Z. (2019). The role of the fibroblast growth factor family in bone-related diseases. Chem. Biol. Drug Des. 94 (4), 1740-1749. doi:10.1111/cbdd.13588

Wang, Y., and Becker, D. (1997). Antisense targeting of basic fibroblast growth factor and dibroblast growth factor receptor-1 in human melanomas blocks intratumoral angiogenesis and tumor growth. Nat. Med. 3 (8), 887-893. doi:10. 1038/nm0897-887

Weiss, A., Adler, F., Buhles, A., Stamm, C., Fairhurst, R. A., Kiffe, M., et al. (2019). FGF401, A first-in-class highly selective and potent FGFR4 inhibitor for the treatment of FGF19-driven hepatocellular cancer. Mol. Cancer Ther. 18 (12), 2194-2206. doi:10.1158/1535-7163.MCT-18-1291

Wu, L., Pan, Q., Wu, G., Qian, L., Zhang, J., Zhang, L., et al. (2017). Diverse changes of circulating fibroblast growth factor 21 levels in hepatitis B virus-related diseases. Sci. Rep. 7 (1), 16482. doi:10.1038/s41598-017-16312-6

Xie, H., Xing, C., Wei, B., Xu, X., Wu, L., Wu, J., et al. (2015). Polymorphisms of FGFR1 in HBV-related hepatocellular carcinoma. Tumor Biol. 36 (11), 8881-8886. doi:10.1007/s13277-015-3643-4

Yang, C., Jin, C., Li, X., Wang, F., McKeehan, W. L., and Luo, Y. (2012a). Differential specificity of endocrine FGF19 and FGF21 to FGFR1 and FGFR4 in complex with KLB. PLoS One 7 (3), e33870. doi:10.1371/journal. pone. 0033870 
Yang, C., Lu, W., Lin, T., You, P., Ye, M., Huang, Y., et al. (2013a). Activation of Liver FGF21 in hepatocarcinogenesis and during hepatic stress. BMC Gastroenterol. 13, 67. doi:10.1186/1471-230X-13-67

Yang, H., Fang, F., Chang, R., and Yang, L. (2013b). MicroRNA-140-5p suppresses tumor growth and metastasis by targeting transforming growth factor $\beta$ receptor 1 and fibroblast growth factor 9 in hepatocellular carcinoma. Hepatology 58 (1), 205-217. doi:10.1002/hep.26315

Yang, L., Yin, D., Wang, Y., and Cao, L. (2017). Inhibition of the growth of hepatocellular carcinoma cells through fibroblast growth factor 18 suppressed by miR-139. Oncol. Rep. 38 (4), 2565-2571. doi:10.3892/or.2017.5869

Yang, Y., Zhou, Y., Lu, M., An, Y., Li, R., Chen, Y., et al. (2012b). Association between fibroblast growth factor receptor 4 polymorphisms and risk of hepatocellular carcinoma. Mol. Carcinog. 51 (7), 515-521. doi:10.1002/mc. 20805

Ye, D., Li, H., Wang, Y., Jia, W., Zhou, J., Fan, J., et al. (2016). Circulating fibroblast growth factor 21 is A sensitive biomarker for severe ischemia/ reperfusion injury in patients with liver transplantation. Sci. Rep. 6, 19776. doi:10.1038/srep19776

Ye, D., Wang, Y., Li, H., Jia, W., Man, K., Lo, C. M., et al. (2014). Fibroblast growth factor 21 protects against acetaminophen-induced hepatotoxicity by potentiating peroxisome proliferator-activated receptor coactivator protein1a-mediated antioxidant capacity in mice. Hepatology 60 (3), 977-989. doi:10. 1002/hep. 27060

Ying, X., Tu, J., Wang, W., Li, X., Xu, C., and Ji, J. (2019). FGFR2-BICC1: a subtype of FGFR2 oncogenic fusion variant in cholangiocarcinoma and the response to sorafenib. Ott 12, 9303-9307. doi:10.2147/OTT.S218796

Yoo, C., Kang, J., Kim, D., Kim, K.-P., Ryoo, B.-Y., Hong, S.-M., et al. (2017). Multiplexed gene expression profiling identifies the FGFR4 pathway as a novel biomarker in intrahepatic cholangiocarcinoma. Oncotarget 8 (24), 38592-38601. doi:10.18632/oncotarget.16951

Yoshiji, H., Kuriyama, S., Yoshii, J., Ikenaka, Y., Noguchi, R., Hicklin, D. J., et al. (2002). Synergistic effect of basic fibroblast growth factor and vascular endothelial growth factor in murine hepatocellular carcinoma. Hepatology 35 (4), 834-842. doi:10.1053/jhep.2002.32541

Yun, Y.-R., Won, J. E., Jeon, E., Lee, S., Kang, W., Jo, H., et al. (2010). Fibroblast growth factors: biology, function, and application for tissue regeneration. J. Tissue Eng. 1, 218142. doi:10.4061/2010/218142

Zhang, J., Tang, P. M. K., Zhou, Y., Cheng, A. S. L., Yu, J., Kang, W., et al. (2019a). Targeting the oncogenic FGF-FGFR Axis in gastric carcinogenesis. Cells 8 (6), 637. doi:10.3390/cells8060637
Zhang, J., Zhou, Y., Huang, T., Wu, F., Pan, Y., Dong, Y., et al. (2019b). FGF18, a prominent player in FGF signaling, promotes gastric tumorigenesis through autocrine manner and is negatively regulated by miR-590-5p. Oncogene 38 (1), 33-46. doi:10.1038/s41388-018-0430-X

Zhang, Q., Li, Y., Liang, T., Lu, X., Liu, X., Zhang, C., et al. (2015). Loss of FGF21 in diabetic mouse during hepatocellular carcinogenetic transformation. Am. J. Cancer Res. 5 (5), 1762-1774.

Zhang, X., Ibrahimi, O. A., Olsen, S. K., Umemori, H., Mohammadi, M., and Ornitz, D. M. (2006). Receptor specificity of the fibroblast growth factor family. J. Biol. Chem. 281 (23), 15694-15700. doi:10.1074/jbc.M601252200

Zhao, H., Lv, F., Liang, G., Huang, X., Wu, G., Zhang, W., et al. (2016). FGF19 promotes epithelial-mesenchymal transition in hepatocellular carcinoma cells by modulating the GSK3 $\beta / \beta$ - catenin signaling cascade via FGFR4 activation. Oncotarget 7 (12), 13575-13586. doi:10.18632/oncotarget.6185

Zhong, L., Fu, X.-Y., Zou, C., Yang, L.-L., Zhou, S., Yang, J., et al. (2014). A preclinical evaluation of a novel multikinase inhibitor, SKLB-329, as a therapeutic agent against hepatocellular carcinoma. Int. J. Cancer 135 (12), 2972-2983. doi:10.1002/ijc.28944

Zhou, M., Yang, H., Learned, R. M., Tian, H., and Ling, L. (2017). Non-cellautonomous activation of IL-6/STAT3 signaling mediates FGF19-driven hepatocarcinogenesis. Nat. Commun. 8, 15433. doi:10.1038/ncomms15433

Zhuang, J., He, S., Wang, G., Wang, G., Ni, J., Zhang, S., et al. (2018). Long noncoding RNA FGFR3-AS1 promotes hepatocellular carcinoma carcinogenesis via modulating the PI3K/AKT pathway. Oncol. Res. 26 (8), 1257-1265. doi:10.3727/096504018X15172756878992

Zou, B., Liu, X., Gong, Y., Cai, C., Li, P., Xing, S., et al. (2018). A novel 12-marker panel of cancer-associated fibroblasts involved in progression of hepatocellular carcinoma. Cmar 10, 5303-5311. doi:10.2147/CMAR.S176152

Conflict of Interest: The authors declare that the research was conducted in the absence of any commercial or financial relationships that could be construed as a potential conflict of interest.

Copyright (C) 2021 Wang, Yang, Zhang, Liu, Li, Su and Song. This is an open-access article distributed under the terms of the Creative Commons Attribution License (CC $B Y)$. The use, distribution or reproduction in other forums is permitted, provided the original author(s) and the copyright owner(s) are credited and that the original publication in this journal is cited, in accordance with accepted academic practice. No use, distribution or reproduction is permitted which does not comply with these terms. 